\title{
Activation cross sections of $\alpha$-particle induced nuclear reactions on hafnium and deuteron induced nuclear reaction on tantalum: production of ${ }^{178} \mathrm{~W} /{ }^{178 m} \mathrm{Ta}$ generator
}

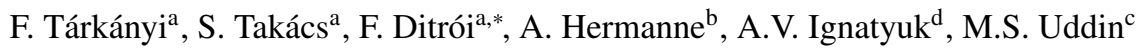 \\ ${ }^{a}$ Institute for Nuclear Research, Hungarian Academy of Sciences (ATOMKI), Debrecen, Hungary \\ ${ }^{b}$ Cyclotron Laboratory, Vrije Universiteit Brussel (VUB), Brussels, Belgium \\ ${ }^{c}$ Cyclotron Radioisotope Center (CYRIC), Tohoku University, Sendai, Japan \\ ${ }^{d}$ Institute of Physics and Power Engineering (IPPE), Obninsk, Russia
}

\begin{abstract}
In the frame of a systematic study of charged particle production routes of medically relevant radionuclei, the excitation function for indirect production of ${ }^{178 m}$ Ta through ${ }^{n a t} \mathrm{Hf}(\alpha, \mathrm{xn})^{178-178 m}$ Ta nuclear reaction was measured for the first time up to $40 \mathrm{MeV}$. In parallel, the side reactions ${ }^{\text {nat }} \mathrm{Hf}(\alpha, \mathrm{x}){ }^{179,177,176,175} \mathrm{~W},{ }^{183,182,178 g, 177,176,175} \mathrm{Ta},{ }^{179 m, 177 m, 175} \mathrm{Hf}$ were also assessed. Stacked foil irradiation technique and $\gamma$-ray spectrometry were used. New experimental cross section data for the ${ }^{\text {nat }} \mathrm{Ta}(\mathrm{d}, \mathrm{xn}){ }^{178} \mathrm{~W}$ reaction are also reported up to $40 \mathrm{MeV}$. The measured excitation functions are compared with the results of the ALICE-IPPE, and EMPIRE nuclear reaction model codes and with the TALYS 1.4 based data in the TENDL-2013 library. The thick target yields were deduced and compared with yields of other charged particle $\left((\mathrm{p}, 4 \mathrm{n}),(\mathrm{d}, 5 \mathrm{n})\right.$ and $\left.\left({ }^{3} \mathrm{He}, \mathrm{x}\right)\right)$ production routes for ${ }^{178} \mathrm{~W}$.
\end{abstract}

Keywords: hafnium and tantalum target, $\alpha$-irradiation, deuteron irradiation, hafnium, tantalum and tungsten radioisotopes, physical yield, ${ }^{178} \mathrm{~W}$ production

\section{Introduction}

The short-lived (9.3 min) metastable state of the ${ }^{178} \mathrm{Ta}$ a radioisotope can be used both for diagnostic (PET studies, total $\beta^{+}$decay: $1.24 \%$ ) as well as for therapeutic purposes $\left(\mathrm{K}_{\alpha 1}+\mathrm{K}_{\alpha} 260 \%\right)$ (Lacy et al. 2001 . Layne and Lacy, 1990; Nichols, 2013, Wilson et al. 1987). It can be produced from long-lived (21.7 d) ${ }^{178} \mathrm{~W}$ via a ${ }^{178} \mathrm{~W} /{ }^{178}$ Ta generator. The used production routes include proton and deuteron induced reactions on tantalum and alpha and ${ }^{3} \mathrm{He}$ particle induced reactions on hafnium. In the frame of a coordinated research project of the IAEA the evaluation of cross sections of production routes of several medical radioisotopes, including the so called generator isotopes, is in progress (Nichols. 2013). The production routes for a ${ }^{178} \mathrm{~W} /{ }^{178} \mathrm{Ta}$ generator were previously compiled (not evaluated) in another IAEA project dealing with the physical characteristics and production methods of cyclotron produced radionuclides (Haji-Saeid et al., 2009). The compilation of the available experimental cross section results showed no

*Corresponding author: ditroi@atomki.hu

Preprint submitted to Applied Radiation and Isotopes satisfactory data set. No cross section data are available for the ${ }^{n a t} \operatorname{Hf}(\alpha, \mathrm{xn})^{178} \mathrm{~W}$ reaction. Among the possible production routes we also measured cross sections (up to $70 \mathrm{MeV}$ ) and made theoretical calculation for the ${ }^{n a t} \mathrm{Ta}(\mathrm{p}, \mathrm{x})^{178} \mathrm{~W}$ reaction (Uddin et al. 2004). We also investigated activation cross sections for deuteron induced reactions on Ta up to $40 \mathrm{MeV}$, but cross section data for ${ }^{178} \mathrm{~W}$ production were not reported (Hermanne et al. 2009). In this work we experimentally investigate the excitation function of the ${ }^{n a t} \mathrm{Hf}(\alpha, \mathrm{xn})^{178} \mathrm{~W}$ reaction and the accompanying side reactions, and by re-evaluating the spectra obtained in our earlier ${ }^{n a t} \mathrm{Ta}(\mathrm{d}, \mathrm{x})$ experiment we report cross sections of the ${ }^{n a t} \mathrm{Ta}(\mathrm{d}, \mathrm{x})^{178} \mathrm{~W}$ reaction. To show the capability of different nuclear reaction codes, the measured excitation functions are compared with the results obtained with ALICE-IPPE, EMPIRE and TALYS 1.4 (data from the TENDL-2013 online library) nuclear reaction codes. The thick target yields were deduced and also compared with yields of other charged particle production routes for ${ }^{178} \mathrm{~W}$. The $\mathrm{Ta}$ is nearly monoisotopic, consists of $99.988 \%{ }^{181} \mathrm{Ta}$ and only $0.012 \%{ }^{180} \mathrm{Ta}$, therefore under the present un- 
certainty levels we can use in the text the ${ }^{n a t} \mathrm{Ta}$ and the ${ }^{181}$ Ta alternately.

\section{Review of earlier measurements of cross section for production of ${ }^{178} \mathrm{~W}$}

A summary of the earlier and the present experimental investigations ( $\mathrm{p}, \mathrm{d}, \alpha$-particle) found in the literature is presented in Table 1. The numerical cross section and yield data of the earlier measurements were taken from the original works, from the NRDC Experimental Nuclear Reaction Data (EXFOR) database (IAEA, 2014) and from the early Landolt- Bornstein (Semenov et al. 1996) compilations.

\section{Theoretical calculations}

The measured cross sections were compared with the theoretical effective cross sections calculated by means of three different nuclear reaction computer model codes. For the pre-compound model codes ALICEIPPE (Dityuk et al., 1998) and EMPIRE-II (Herman et al. 2007) the parameters for the optical model, level densities and pre-equilibrium contributions were taken as described in (Belgya et al. 2005). The third set of theoretical values on the figures represent data taken from the TENDL-2013 online library (Koning et al. 2012) calculated with the 1.4 version of TALYS (Koning et al., 2007). The cross sections for isomers in the case of the ALICE code were obtained by using the isomeric ratios calculated with EMPIRE code.

\section{Experimental techniques and data evaluation}

\subsection{The experimental techniques for the ${ }^{\text {nat }} H f(\alpha, x)$ ex- periment}

The experimental method used was similar to that described in our numerous earlier investigations of charged particle induced nuclear reactions for production of medically relevant radioisotopes. Here we report only the most salient features related to reliability of the measured data in table form (see Table 2). The excitation functions were measured by activation method using the stacked foil technique. Commercial, high purity (Goodfellow) Hf target foils and Ti monitor foils were interleaved in a stack to measure the unknown excitation functions of the radionuclides produced in $\mathrm{Hf}$ and to re-measure the well-known excitation function of the monitor reaction in parallel. The thickness and the uniformity of the used targets were determined by weighing the original metal sheets and the individual

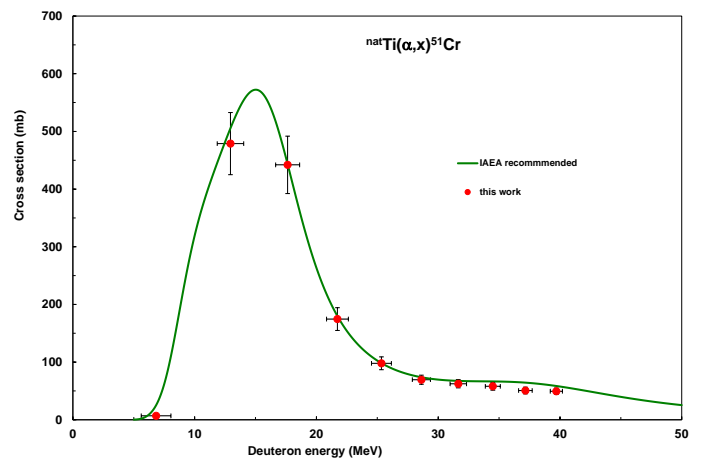

Figure 1: Comparison of the simultaneously measured ${ }^{\text {nat }} \mathrm{Ti}(\alpha, \mathrm{x})^{51} \mathrm{Cr}$ monitor reaction with the recommended curve

target foils. The target stack was irradiated at the external beam line of the CGR560 cyclotron of the Vrije Universiteit Brussel (VUB) in a Faraday-cup-like holder to control the beam intensity parameters. The primary beam energy was estimated from the parameters of the accelerator and from the extraction, calibrated by TOF method (Sonck et al., 1996). The excitation function of the simultaneously measured monitor reaction ${ }^{n a t} \operatorname{Ti}(\alpha, \mathrm{x}){ }^{51} \mathrm{Cr}$ is shown in Fig. 1 in comparison with the recommended data taken from (Tárkányi et al. 2001). An excellent agreement was found after small corrections of the beam intensity ( $5 \%$ relative to the Faraday cup results) and of the primary beam energy $(0.3 \mathrm{MeV})$. The decay data were taken from NUDAT 2.6 library (NuDat 2014), except for a few isotopes (not detailed in NUDAT), for which the decay data are taken from the LBL library (marked in the discussion) (Firestone and Ekstrm, 2004). The uncertainty of the energy was increasing from $0.3 \mathrm{MeV}$ for the first foil to $1.5 \mathrm{MeV}$ at the end of the stack. The cross section uncertainties are in the 10-20\% range and were calculated by using the activation and decay formulas. The uncertainty of cross-sections was derived by summing in quadrature of all individual contributions (beam current (7\%), beam-loss corrections ( $\max$. of $1.5 \%$ ), target thickness (3\%), detector efficiency $(5 \%)$, photo peak area determination and counting statistics (1-20\%)). The contributions of the uncertainties of non-linear parameters were neglected (cooling times, half-life). The samples were measured at relatively large distances from the detector surface $(>5 \mathrm{~cm})$ in order to consider them as point-like sources and ensure a better reproducibility. 
Table 1: Experimental circumstances of the referred measurements

\begin{tabular}{|c|c|c|c|c|c|c|}
\hline Author & Target & Irradiation & Beam current monitor reaction & Measurement of activity & Reaction, data points & $\begin{array}{l}\text { Energy range } \\
(\mathrm{MeV})\end{array}$ \\
\hline \multicolumn{7}{|c|}{${ }^{181} \mathbf{T a}(\mathbf{p}, \mathbf{4 n})^{178} \mathbf{W}$} \\
\hline $\begin{array}{l}\text { Rao et al. } \\
\text { (1963) } \\
\text { Exfor: C0402 }\end{array}$ & $\begin{array}{l}{ }^{n a t} \mathrm{Ta} \\
84.3 \text { and } 21 \mathrm{mg} / \mathrm{cm}^{2}\end{array}$ & $\begin{array}{l}\text { Synchrotron: } \\
\text { stacked foil } \\
\text { technique }\end{array}$ & $\begin{array}{l}\left.{ }^{63} \mathrm{Cu}(\mathrm{p}, \mathrm{n})\right)^{63} \mathrm{Zn} \\
{ }^{63} \mathrm{Cu}(\mathrm{p}, \mathrm{np}){ }^{64} \mathrm{Cu}\end{array}$ & $\begin{array}{l}\text { Chemical sep., } \\
\gamma \text {-NaI(Tl) }\end{array}$ & ${ }^{n a t} \mathrm{Ta}(\mathrm{p}, 4 \mathrm{n})$ No. 8 & $30-84$ \\
\hline 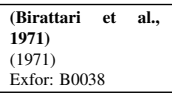 & $\begin{array}{l}{ }^{n a t} \mathrm{Ta} \\
20 \mu \mathrm{m}\end{array}$ & $\begin{array}{l}\text { cyclotron: } \\
\text { stacked foil } \\
\text { technique }\end{array}$ & Faraday cup & $\gamma-\mathrm{NaI}(\mathrm{Tl})$ & ${ }^{181} \mathrm{Ta}(\mathrm{p}, 4 \mathrm{n})^{178} \mathrm{~W}$, No. 8 & $28-44.2$ \\
\hline 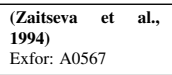 & $\begin{array}{l}{ }^{n a t} \mathrm{Ta} \\
0.20 \mathrm{~g} / \mathrm{cm}^{2} \\
0.148 \mathrm{~g} / \mathrm{cm}^{2}\end{array}$ & $\begin{array}{l}\text { Linac: } \\
\text { Stacked foil technique }\end{array}$ & $\begin{array}{l}\text { Faraday cup } \\
{ }^{27} \mathrm{Al}(\mathrm{p}, \mathrm{x})^{24} \mathrm{Na}\end{array}$ & $\begin{array}{l}\text { No chemical separation } \\
\gamma \text {-Ge(Li) }\end{array}$ & ${ }^{181} \mathrm{Ta}(\mathrm{p}, 4 \mathrm{n})^{178} \mathrm{~W}$, No. 32 & $28.8-78.8$ \\
\hline $\begin{array}{l}\text { Michel et al. 2001 } \\
\text { (2002) } \\
\text { Exfor: O1099 } \\
\end{array}$ & ${ }^{n a t} \mathrm{Ta}$ & $\begin{array}{l}\text { cyclotron: } \\
\text { synchrotron } \\
\text { stacked foil technique }\end{array}$ & $\begin{array}{l}{ }^{27} \mathrm{Al}(\mathrm{p}, \mathrm{x})^{24} \mathrm{Na} \\
{ }^{n a t} \mathrm{Cu}(\mathrm{p}, \mathrm{x})^{65} \mathrm{Zn}\end{array}$ & $\begin{array}{l}\text { No chemical separation } \\
\gamma \text {-HpGe }\end{array}$ & ${ }^{181} \mathrm{Ta}(\mathrm{p}, 4 \mathrm{n})^{178} \mathrm{~W}, \mathrm{No} .24$ & $70.8-2580$ \\
\hline $\begin{array}{l}\text { Uddin et al. 2004 } \\
\text { (2004) } \\
\text { Exfor: E1981 }\end{array}$ & $\begin{array}{l}{ }^{n a t} \mathrm{Ta} \\
10 \mathrm{~mm}\end{array}$ & $\begin{array}{l}\text { Cyclotron: } \\
\text { stacked foil technique }\end{array}$ & $\begin{array}{l}n{ }^{n a t} \mathrm{Cu}(\mathrm{p}, \mathrm{x})^{58} \mathrm{Co} \\
{ }^{27} \mathrm{Al}(\mathrm{p}, \mathrm{x})^{24} \mathrm{Na}\end{array}$ & $\begin{array}{l}\text { No chemical separation } \\
\gamma \text {-HpGe }\end{array}$ & $\left.{ }^{181} \mathrm{Ta}(\mathrm{p}, 4 \mathrm{n})\right)^{178} \mathrm{~W}$, No. 12 & $28.6-69.0$ \\
\hline $\begin{array}{l}\text { Titarenko et al. } \\
\text { 2011) } \\
\text { (2011) } \\
\text { Exfor: A0904 } \\
\end{array}$ & $\begin{array}{l}{ }^{n a t} \mathrm{Ta} 256-270.9 \mathrm{mg} \\
{ }^{181} \mathrm{Ta} 48-59.1 \mathrm{mg}\end{array}$ & synchrotron & ${ }^{27} \mathrm{Al}(\mathrm{p}, \mathrm{x})^{24} \mathrm{Na}$ & $\begin{array}{l}\text { No chemical } \\
\text { separation, } \mathrm{g} \text {-HpGe }\end{array}$ & ${ }^{n a t} \mathrm{Ta}(\mathrm{p}, 4 \mathrm{n}){ }^{178} \mathrm{~W}$, No. 10 & 43-1598 \\
\hline \multicolumn{7}{|l|}{${ }^{181} \mathbf{T a}(\mathbf{d}, \mathbf{5 n})^{178} \mathbf{W}$} \\
\hline $\begin{array}{l}\text { Bisplinghoff et al. } \\
\text { 1974 } \\
\text { (1974) } \\
\text { Exfor A0283 } \\
\end{array}$ & $\begin{array}{l}{ }^{n a t} \mathrm{Ta} \\
20 \text { and } 100 \mathrm{~mm}\end{array}$ & $\begin{array}{l}\text { Cyclotron: } \\
\text { stacked foil technique }\end{array}$ & ${ }^{27} \mathrm{Al}(\mathrm{d}, \mathrm{x}){ }^{24} \mathrm{Na}$ & $\begin{array}{l}\text { No chemical separation } \\
\mathrm{g} \text {-Ge(Li) }\end{array}$ & ${ }^{181} \mathrm{Ta}(\mathrm{d}, 5 \mathrm{n}){ }^{178} \mathrm{~W}, \mathrm{No} .14$ & $37.8-79.2$ \\
\hline $\begin{array}{l}\text { Tárkányi et al. } \\
\text { (2014) } \\
\text { this work } \\
\text { Exfor: No }\end{array}$ & ${ }^{n a t} \mathrm{Ta} 25 \mathrm{~mm}$ & $\begin{array}{l}\text { Cyclotron: } \\
\text { stacked foil technique }\end{array}$ & $\begin{array}{l}{ }^{n a t} \mathrm{Ti}(\mathrm{d}, \mathrm{x})^{48} \mathrm{~V} \\
{ }^{27} \mathrm{Al}(\mathrm{d}, \mathrm{x})^{22,24} \mathrm{Na}\end{array}$ & $\begin{array}{l}\text { No chemical } \\
\text { separation, } \gamma \text {-HpGe }\end{array}$ & ${ }^{181} \mathrm{Ta}(\mathrm{d}, 5 \mathrm{n})^{178} \mathrm{~W}$, No. 8 & $29.6-39.8$ \\
\hline \multicolumn{7}{|c|}{${ }^{n a t} \mathbf{H f}(\mathbf{a}, \mathbf{x n})^{178} \mathbf{W}$} \\
\hline $\begin{array}{l}\text { Tárkányi et al. } \\
\text { (2014) } \\
\text { This work } \\
\text { Exfor: No }\end{array}$ & $\begin{array}{l}{ }^{n a t} \mathrm{Hf} \\
9.62 \mathrm{~mm}\end{array}$ & $\begin{array}{l}\text { cyclotron: stacked foil tech- } \\
\text { nique }\end{array}$ & $\begin{array}{l}\text { Faraday cup } \\
\text { nat }_{\mathrm{Ti}(\mathrm{a}, \mathrm{x})^{51} \mathrm{Cr}}\end{array}$ & $\begin{array}{l}\text { No chemical separation } \\
\gamma \text {-HpGe }\end{array}$ & ${ }^{n a t} \mathrm{Hf}(\mathrm{a}, \mathrm{xn})^{178} \mathrm{~W}$, No.9 & $14.5-38.9$ \\
\hline
\end{tabular}

\subsection{The experimental techniques for the ${ }^{n a t} \mathrm{Ta}(d, x)^{178} \mathrm{~W}$ experiment}

The experimental method, origin of decay data and handling of uncertainties are similar as described in the previous paragraph and were reported in detail in our previous work on ${ }^{n a t} \mathrm{Ta}(\mathrm{d}, \mathrm{x})$ reactions up to $40 \mathrm{MeV}$ deuteron energy (Hermanne et al. 2009).

\section{Results}

\subsection{Cross sections}

\subsubsection{Cross sections of the ${ }^{\text {nat }} H f(\alpha, x)^{179,177,176,175} W$, ${ }^{183,182,178 g, 177,176,175} \mathrm{Ta},{ }^{179 m, 177 m, 175} \mathrm{H}$ f reactions}

The cross sections for all activation products assessed for the ${ }^{n a t} \operatorname{Hf}(\alpha, \mathrm{x})$ experiment are shown in Figures 217 and the numerical values are presented in Tables 4-6. The reactions responsible for the production of a given activation product and their Q-values are given in Table 3 . The radioisotopes of $\mathrm{W}$ are produced via $(\alpha, \mathrm{xn})$ reactions, the tantalum radioisotopes by $(\alpha, \mathrm{pxn})$ and by $\mathrm{EC}-\beta^{+}$of $\mathrm{W}$ and by $\beta^{-}$-decay $\mathrm{Hf}$ radioisotopes, the $\mathrm{Hf}$ radioisotopes are produced by $(\alpha, 2 \mathrm{pxn})$ and $\mathrm{EC}$ of Ta.

\subsubsection{Production of ${ }^{179} W$}

The measured cross sections for ${ }^{179} \mathrm{~W}\left(T_{1 / 2}=37.05\right.$ min) production include the full contribution of the decay of the short-lived isomer $\left(T_{1 / 2}=6.40 \mathrm{~min}\right.$, IT: $99.71 \%)$. The experimental and theoretical excitation functions are shown in Fig. 2. In case of ALICE and EMPIRE the total production cross section is given for ${ }^{n a t} \operatorname{Hf}(\alpha, \mathrm{xn}){ }^{179} \mathrm{~W}$. The isomeric ratio for the isomer $1 / 2^{-}$ is less than 0.03 and the calculated isomer production is about 30-50 times lower. The values of the theoretical codes are systematically higher, but the agreement between the experimental and theoretical data is more or less acceptable.

\subsubsection{Production of ${ }^{178} \mathrm{~W}$}

In the decay of the long-lived ${ }^{178} \mathrm{~W}\left(T_{1 / 2}=21.6 \mathrm{~d}\right)$ no measurable $\gamma$-rays are generated. The production cross section of ${ }^{178} \mathrm{~W}$ can however be assessed through $\gamma$-lines of the short-lived ${ }^{178 g} \mathrm{Ta}$ daughter radioisotope $\left(T_{1 / 2}=\right.$ $9.31 \mathrm{~min}$ ) after the complete decay of the directly produced $178 \mathrm{gTa}\left(T_{1 / 2}=2.45 \mathrm{~h}\right)$. The experimental and model cross sections are shown in Fig. 3. The best approximation is given by the EMPIRE and TALYS codes.

\subsubsection{Production of ${ }^{177} \mathrm{~W}$}

The measured activation cross sections of ${ }^{177} \mathrm{~W}\left(T_{1 / 2}=\right.$ $132 \mathrm{~min}$ ) are shown in Fig. 4. The agreement with the model calculations ranges from acceptable to good. 
Table 2: Main experimental parameters and main parameters and methods of the data evaluation of the a-particle induced reactions

\begin{tabular}{|c|c|c|c|}
\hline \multicolumn{2}{|l|}{ Main experimental parameters } & \multicolumn{2}{|l|}{ Methods of the data evaluation } \\
\hline Incident particle & $\alpha$ (VUB) & $\gamma$-spectra evaluation & $\begin{array}{l}\text { Genie 2000, Forgamma Canberra 2000, Székely. } \\
1985 \text {. }\end{array}$ \\
\hline Method & Stacked foil & Determination of beam intensity & $\begin{array}{l}\text { Faraday cup (preliminary) } \\
\text { Fitted monitor reaction (final) Tárkányi et al.. } 1991 .\end{array}$ \\
\hline Target composition & $\begin{array}{l}\mathrm{nal}_{\mathrm{Hf}}(9.62 \mu \mathrm{m}) \text { )-target } \\
\mathrm{Ti}(10.9 \mu \mathrm{m}) \text {-monitor } \\
\text { (repeated } 9 \text { times) }\end{array}$ & Determination of primary beam energy & $\begin{array}{l}\text { Cyclotron parameters } \\
\text { calibrated with TOF [Sonck et al. 1996] } \\
\text { Fitted monitor reaction (final) [árkányi et al. 1991]. }\end{array}$ \\
\hline Number of $\mathrm{Hf}$ target foils & 9 & Decay data (Table 3 ) & $\begin{array}{l}\text { NUDAT 2.6 } \\
\text { and LBDNat, 2014 } \\
\text { [sotopes Project Firestone and Ekstrm. }\end{array}$ \\
\hline Accelerator & CGR 560 cyclotron Vrije Universiteit Brussels & Reaction Q-values(Table 3) & Q-value calculator Pritychenko and Sonzogni 2003 \\
\hline Primary energy & $39.4 \mathrm{MeV}$ & $\begin{array}{l}\text { Determination of beam energy } \\
\text { in the targets }\end{array}$ & $\begin{array}{l}\text { Andersen (preliminary) Ziegler, } 1977 \text {. } \\
\text { Fitted monitor reaction (final) } \\
\text { Tárkányi et al. 1991] }\end{array}$ \\
\hline Covered energy range & $38.9-14.5 \mathrm{MeV}$ & Uncertainty of energy & $\begin{array}{l}\text { Cumulative eftects of possible uncertainties } \\
\text { (primary energy, target thickness, energy straggling, } \\
\text { correction to monitor reaction) }\end{array}$ \\
\hline Irradiation time & $60 \mathrm{~min}$ & Cross sections & Isotopic and elemental cross sections \\
\hline Beam current & $100 \mathrm{nA}$ & Uncertainty of cross sections & $\begin{array}{l}\text { sum in quadrature of all individual contributions: } \\
\text { beam current }(7 \%) \text {, beam-loss corrections (max. } \\
1.5 \%) \text {, target thickness }(1 \%) \text {, detector efficiency }(5 \%) \text {, } \\
\text { photo peak area determination and counting statistics } \\
\text { of-Weights-and Measures } 1993 \text {. }\end{array}$ \\
\hline Monitor reaction, [recommended values] & $\begin{array}{l}\text { nat }^{n a} \mathrm{Ti}(\mathrm{a}, \mathrm{x})^{5 \mathrm{I}} \mathrm{Cr} \text { reaction } \\
\text { (re-meárkányi et al. } 2001\end{array}$ & Yield & Physical yield Bonardi. 1987 \\
\hline Monitor target and thickness & ${ }^{n a l} \mathrm{Ti}, 10.9 \mu \mathrm{m}$ & & \\
\hline detector & HPGe & & \\
\hline Chemical separation & no & & \\
\hline$\gamma$-spectra measurements & 3 series & & \\
\hline $\begin{array}{l}\text { Cooling times } \\
\text { (and corresponding target-detector distances) }\end{array}$ & $\begin{array}{l}0.4-2.2 \mathrm{~h}(20 \mathrm{~cm}) \\
3.0-4.5 \mathrm{~h}(15 \mathrm{~cm}) \\
415-464 \mathrm{~h}(5 \mathrm{~cm})\end{array}$ & & \\
\hline
\end{tabular}

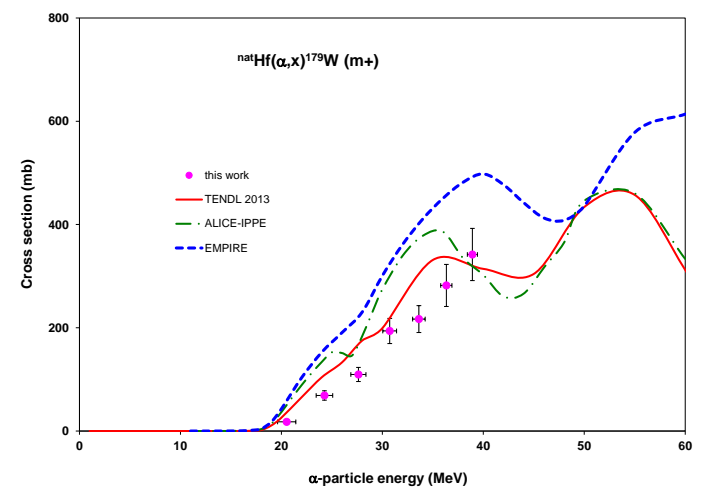

Figure 2: Experimental and theoretical excitation functions for ${ }^{n a t} \mathrm{Hf}(\alpha, \mathrm{xn}){ }^{179} \mathrm{~W}$

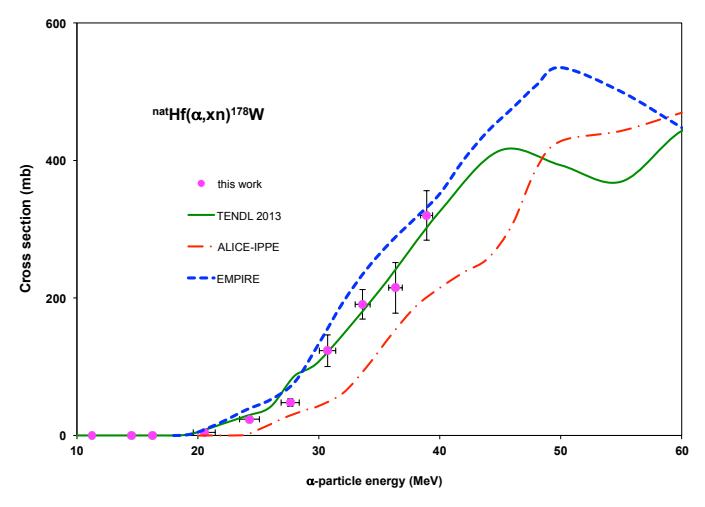

Figure 3: Experimental and theoretical excitation functions for ${ }^{n a t} \mathrm{Hf}(\alpha, \mathrm{xn}){ }^{178} \mathrm{~W}$ 


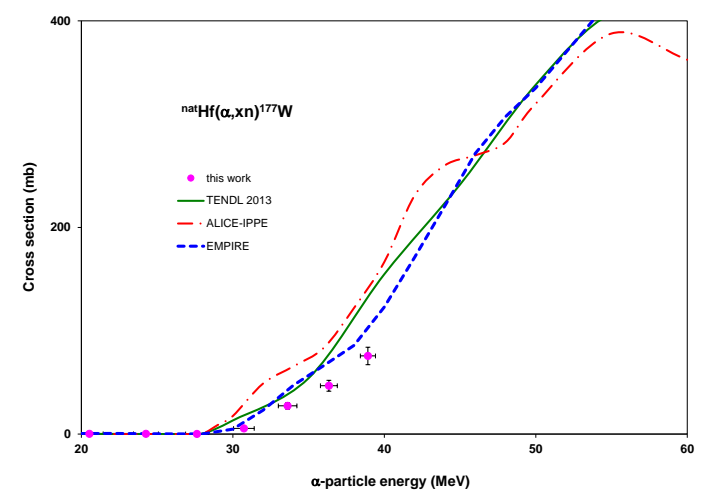

Figure 4: Experimental and theoretical excitation functions for ${ }^{\text {nat }} \mathrm{Hf}(\alpha, \mathrm{xn})^{177} \mathrm{~W}$

\subsubsection{Production of ${ }^{176} W$}

No datasets were found for the decay characteristics of ${ }^{176} \mathrm{~W}\left(T_{1 / 2}=2.5 \mathrm{~h}\right)$ in NUDAT 2.6. The LBL decay database contains only relative intensities for the decay $\gamma$-lines. We calculated cross sections assuming a $100 \%$ absolute intensity for the most abundant $100.20 \mathrm{keV} \gamma$ line. According to Fig. 5 the magnitudes of experimental and the theoretical cross sections are comparable. In fact, in the investigated energy range production is only seen on the very low abundance ${ }^{174} \mathrm{Hf}$, rise starts (according to the theory) by reaction on ${ }^{176} \mathrm{Hf}$ (threshold: $33 \mathrm{MeV}$ ).

\subsubsection{Production of ${ }^{175} \mathrm{~W}$}

For ${ }^{175} \mathrm{~W}\left(T_{1 / 2}=35.2 \mathrm{~min}\right)$ no decay datasets were found in NUDAT 2.6. The energies and intensities of the $\gamma$-lines were taken from the LBL decay database. The shapes of the experimental and the theoretical data are similar in the overlapping energy range, but the theoretical data are systematically higher (Fig. 6).

\subsubsection{Production of ${ }^{183} \mathbf{T a}$}

The ${ }^{183} \mathrm{Ta}\left(T_{1 / 2}=5.1 \mathrm{~d}\right)$ can only be produced via the ${ }^{180} \mathrm{Hf}(\alpha, \mathrm{p})$ reaction. For ${ }^{n a t} \mathrm{Hf}(\alpha, \mathrm{x})^{183} \mathrm{Ta}$ and ${ }^{n a t} \mathrm{Hf}(\alpha, \mathrm{X})^{182 m}$ Ta the EMPIRE code gives too low cross sections Fig. 7 and 8). It is assumed to be a consequence of a bad pre-equilibrium model for the alpha induced reaction. The ALICE results look quite reasonable for both reactions.

\subsubsection{Production of ${ }^{182} \mathbf{T a}$}

The measured cross section of ${ }^{182} \mathrm{Ta}\left(T_{1 / 2}=114.74 \mathrm{~d}\right)$ includes the full contribution of the decay of the short-

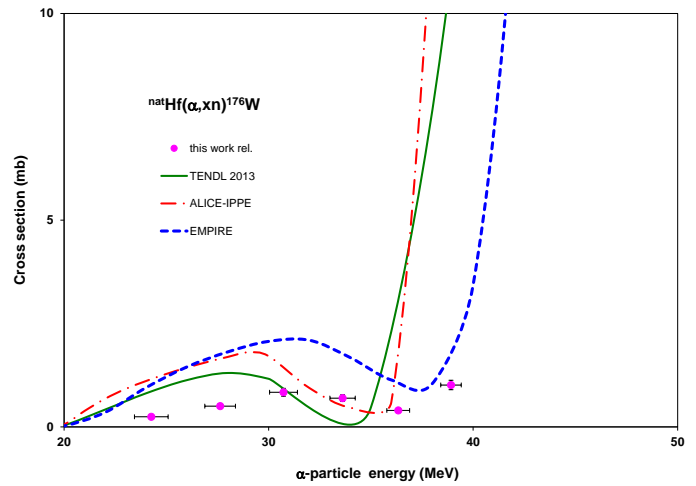

Figure 5: Experimental and theoretical excitation functions for ${ }^{n a t} \operatorname{Hf}(\alpha, \mathrm{xn}){ }^{176} \mathrm{~W}$

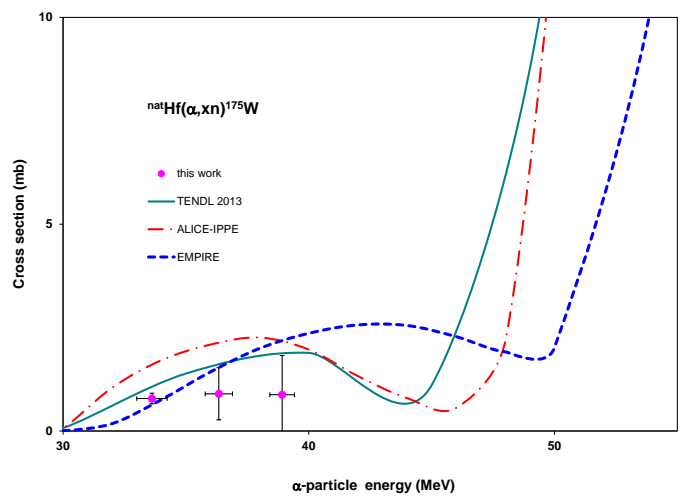

Figure 6: Experimental and theoretical excitation functions for ${ }^{n a t} \operatorname{Hf}(\alpha, \mathrm{xn}){ }^{175} \mathrm{~W}$ 


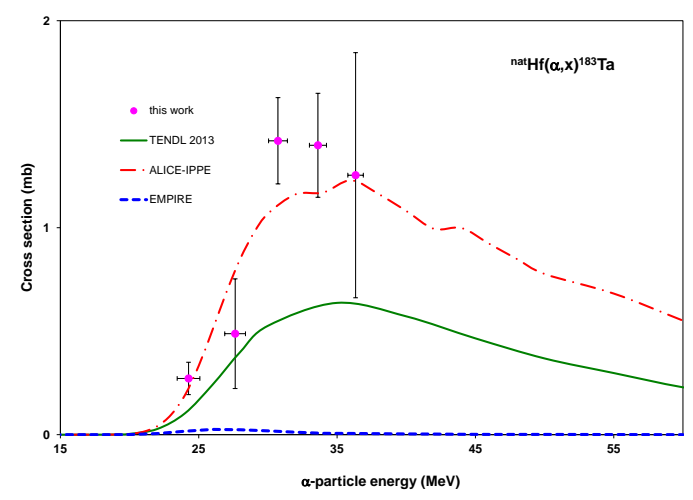

Figure 7: Experimental and theoretical excitation functions for ${ }^{n a t} \operatorname{Hf}(\alpha, \mathrm{x}){ }^{183} \mathrm{Ta}$

lived isomeric states $\left(T_{1 / 2}=15.84 \mathrm{~min}, \mathrm{IT}: 100 \%\right.$ and $283 \mathrm{~ms}$, IT: $100 \%$ ). According to Fig. 8 the ALICE code gives the best agreement with the experiment.

\subsubsection{Production of ${ }^{178 m} \mathbf{T a}$}

For the high spin state of ${ }^{178 m} \mathrm{Ta}\left(T_{1 / 2}=2.36 \mathrm{~h}, \mathrm{I}^{\pi}=\right.$ 7-) no decay datasets were found in NUDAT 2.6; the data were taken from (Firestone and Ekstrm, 2004). Decay of ${ }^{178} \mathrm{~W}$ does not contribute to the population of this sate of ${ }^{178 m} \mathrm{Ta}$. The experimental data are significantly higher than the predictions of the theoretical codes (Fig. 9). No experimental data were found for the production of the $9.31 \mathrm{~min}$ half-life $(1+){ }^{178} \mathrm{Ta}$ ground-state due to the short half-life. The results of our model calculations are shown in Fig. 10.

\subsubsection{Production of ${ }^{177}$ Ta}

The cumulative cross sections of ${ }^{177} \mathrm{Ta}\left(T_{1 / 2}=56.56 \mathrm{~h}\right)$ include the direct production and the contribution from the decay of ${ }^{177} \mathrm{~W}\left(T_{1 / 2}=132 \mathrm{~min},: 100 \% \beta^{+}\right)$. Cross section is nearly the same as for ${ }^{177} \mathrm{~W}$. A small contribution from direct reaction exists. The experimental data are in good agreement with the predictions of the different model codes for cumulative production (Fig. 11). Also the TENDL-2013 prediction for the direct production confirms our conclusion from the experiment.

\subsubsection{Production of ${ }^{176} \mathrm{Ta}$}

The cross section data for production of ${ }^{176} \mathrm{Ta}\left(T_{1 / 2}=\right.$ $8.09 \mathrm{~h})$ are cumulative including full contribution of nearly total decay of ${ }^{176} \mathrm{~W}\left(T_{1 / 2}=2.5 \mathrm{~h}\right)$. We obtained only a few cross section data near the effective threshold. The direct production is significantly lower, com-

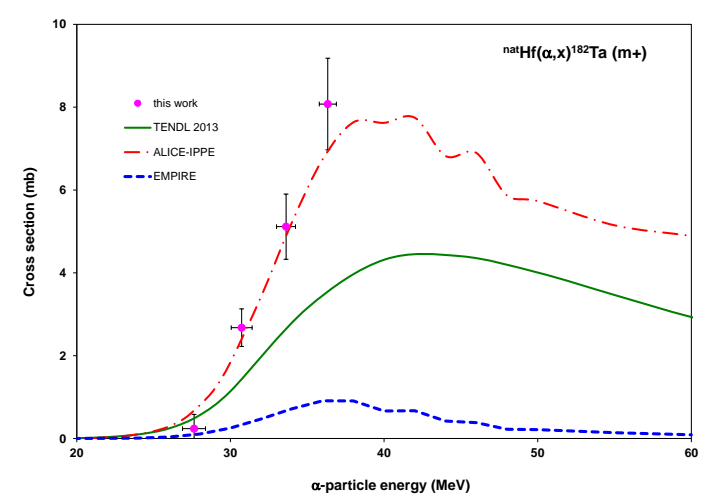

Figure 8: Experimental and theoretical excitation functions for ${ }^{n a t} \operatorname{Hf}(\alpha, \mathrm{x})^{182} \mathrm{Ta}$

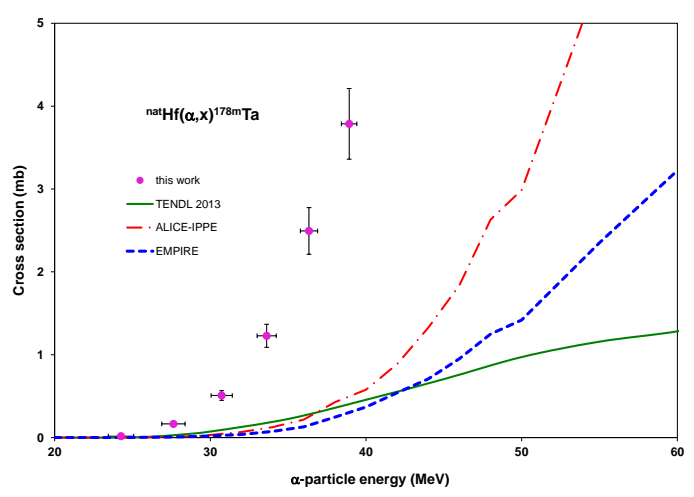

Figure 9: Experimental and theoretical excitation functions for ${ }^{n a t} \mathrm{Hf}(\alpha, \mathrm{X})^{178 m} \mathrm{Ta}$ 


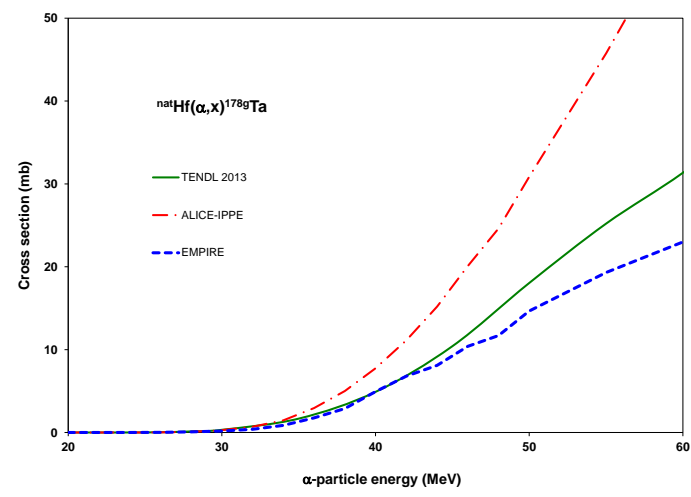

Figure 10: Theoretical excitation functions for ${ }^{n a t} \mathrm{Hf}(\alpha, \mathrm{x})^{178 g} \mathrm{Ta}$

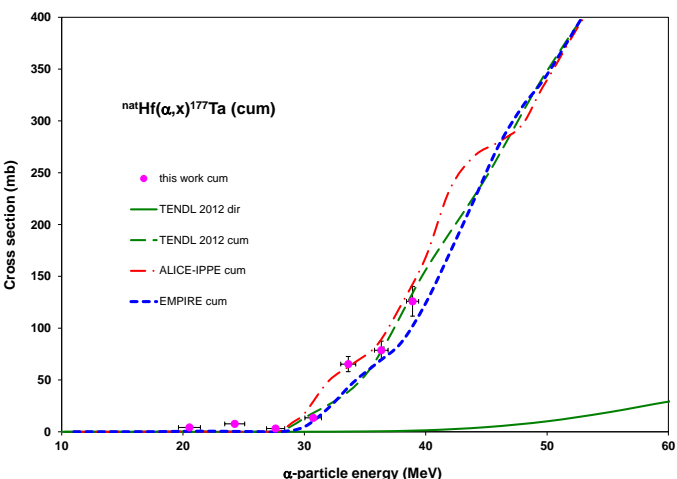

Figure 11: Experimental and theoretical excitation functions for ${ }^{n a t} \operatorname{Hf}(\alpha, \mathrm{x}){ }^{177} \mathrm{Ta}$

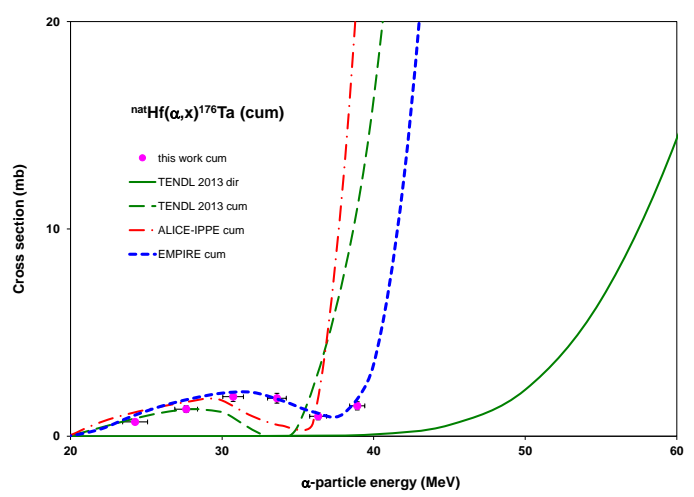

Figure 12: Experimental and theoretical excitation functions for ${ }^{n a t} \mathrm{Hf}(\alpha, \mathrm{x})^{176} \mathrm{Ta}$

pared to the indirect one (Fig. 12).

\subsubsection{Production of ${ }^{175} \mathrm{Ta}$}

The measured cumulative cross sections of the ${ }^{175} \mathrm{Ta}$ $\left(T_{1 / 2}=10.5 \mathrm{~h}\right)$ are shown in Fig. 13 in comparison with the theory. The cumulative cross sections were deduced from $\gamma$-spectra measured after nearly complete decay of the ${ }^{175} \mathrm{~W}$ parent isotope $\left(T_{1 / 2}=35.2 \mathrm{~min}\right)$. The three codes reproduce the cumulative experimental excitation function well. According to Fig. 13 the main contribution is indirect.

\subsubsection{Production of ${ }^{179 m} \mathbf{H f}$}

In only one spectrum could we identify signal with acceptable statistics from the strong $\gamma$-line at $362 \mathrm{keV}$, indicating the presence of the long-lived isomeric state of ${ }^{179 m} \mathrm{Hf}(25 / 2)^{-}, T_{1 / 2}=25.05 \mathrm{~d}$, IT: $\left.100 \%\right)$. The very low corresponding cross section for production via $(\alpha, 2 \mathrm{pxn})$ reactions on higher mass stable $\mathrm{Hf}$ isotopes is indicated in Fig. 14. The magnitude of the predictions of ALICE and EMPIRE are lower compared to the experimental values (see Fig. 14). No theoretical data in the TENDL-2013 library exist.

\subsubsection{Production of ${ }^{177 m} \mathbf{H f}$}

The ${ }^{177 m 2} \mathrm{Hf}(37 / 2)^{-}, T_{1 / 2}=51.4 \mathrm{~min}$, IT: $\left.100 \%\right)$ is produced directly via $(\alpha, 2 \mathrm{pxn})$ reactions. No theoretical data are reported in TENDL-2013 for production of ${ }^{177 m}{ }^{2} \mathrm{Hf}$. The experimental data are comparable with the results predicted by the other two model codes (see Fig. 15).

\subsubsection{Production of ${ }^{175} \mathbf{H f}$}




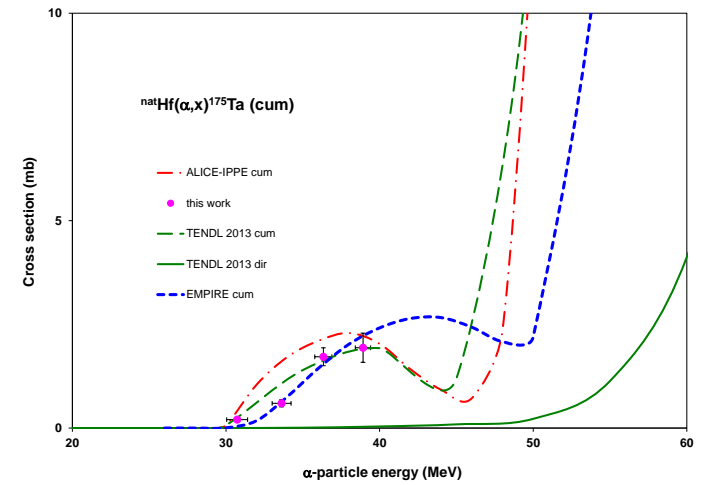

Figure 13: Experimental and theoretical excitation functions for ${ }^{n a t} \operatorname{Hf}(\alpha, \mathrm{x})^{175} \mathrm{Ta}$

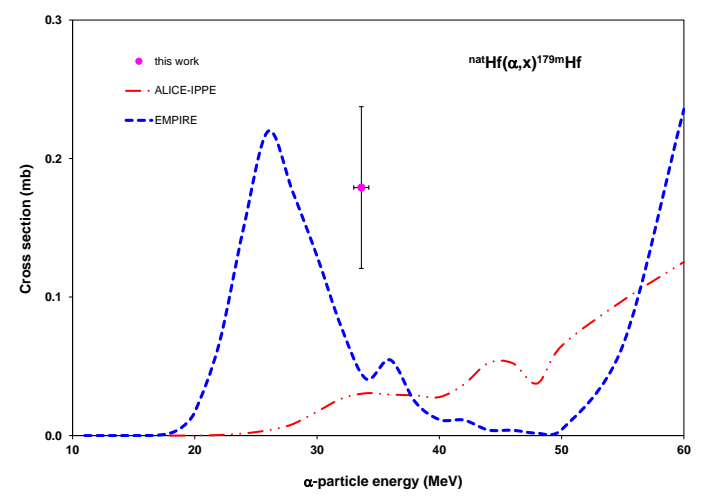

Figure 14: Experimental and theoretical excitation functions for ${ }^{n a t} \operatorname{Hf}(\alpha, \mathrm{x}){ }^{179 m} \mathrm{Ta}$

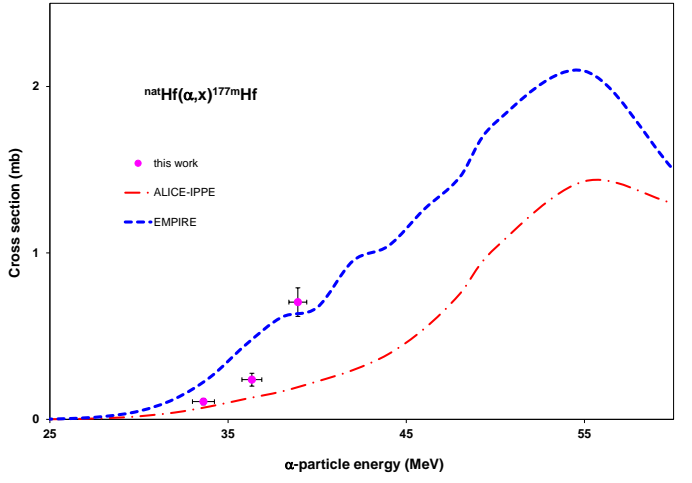

Figure 15: Experimental and theoretical excitation functions for ${ }^{n a t} \operatorname{Hf}(\alpha, \mathrm{x}){ }^{177 m T a}$

The cumulative cross sections of ${ }^{175} \mathrm{Hf}\left(T_{1 / 2}=70 \mathrm{~d}\right)$ represent the sum of direct ( $\alpha, 2 \mathrm{pxn})$ reactions and indirect production through the decay of the ${ }^{175} \mathrm{~W}\left(T_{1 / 2}=\right.$ $35.2 \mathrm{~min})-{ }^{175} \mathrm{Ta}\left(T_{1 / 2}=10.5 \mathrm{~h}\right)$ chain. The results of the model codes are higher compared to the one single measured value; only the EMPIRE code gives acceptable approximation (Fig. 16).

\subsubsection{Cross sections of the ${ }^{n a t} \mathrm{Ta}(d, x n)^{178} \mathrm{~W}$ reaction}

The cross sections for the ${ }^{n a t} \mathrm{Ta}(\mathrm{d}, \mathrm{xn}){ }^{178} \mathrm{~W}$ reaction are shown in Fig. 17 and the numerical values are presented in Table 5. The reactions responsible for the production of a given activation product and their Q-values are given in Table 3. Practically, only the ${ }^{181} \mathrm{Ta}(\mathrm{d}, 5 \mathrm{n})$ reaction can contribute to the formation of ${ }^{178} \mathrm{~W}$, as the abundance of the quasi-stable ${ }^{180} \mathrm{Ta}$ in ${ }^{n a t} \mathrm{Ta}$ is only $0.012 \%$. The earlier reported experimental excitation function of (Bisplinghoff et al., 1974) seems to be shifted to higher energy. The data in the TENDL-2013 library are acceptable, but shifted to lower energies. The best approximation is given by the EMPIRE code in our energy range.

\subsection{Integral production yields}

Thick target yields (integrated yield for a given incident energy down to the reaction threshold) were calculated from fitted curves to our experimental cross section data. The results for physical yields (production rate) (Bonardi, 1987) are presented in Fig. 18-19. No earlier experimental thick target yield data were found in the literature. 


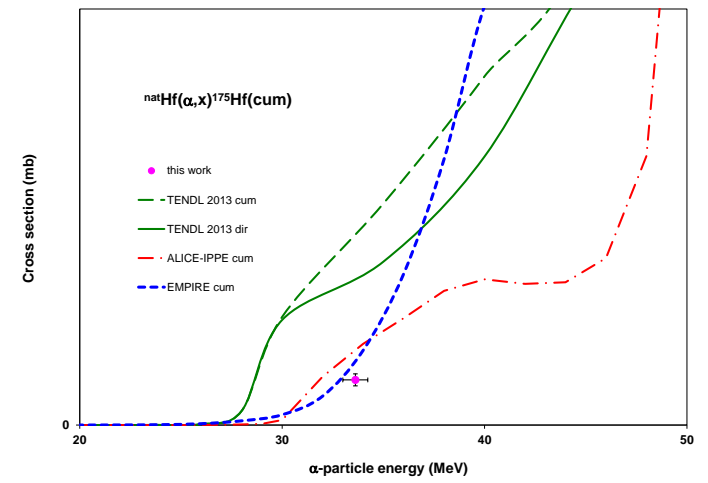

Figure 16: Experimental and theoretical excitation functions for ${ }^{n a t} \operatorname{Hf}(\alpha, \mathrm{x}){ }^{176} \mathrm{Ta}$

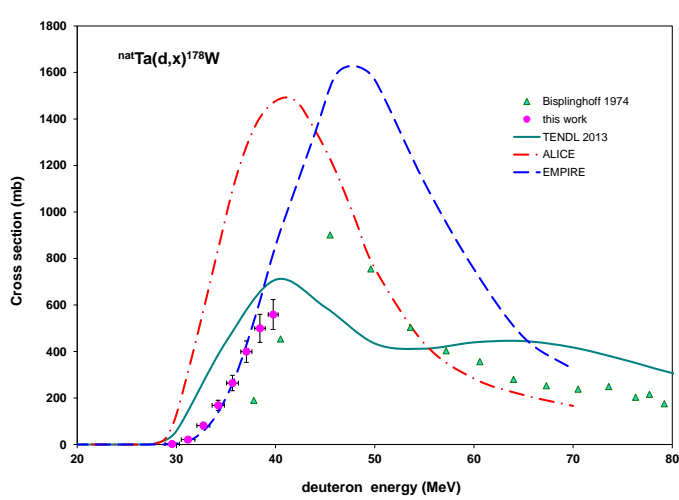

Figure 17: Experimental and theoretical excitation functions for ${ }^{181} \mathrm{Ta}(\mathrm{d}, 5 \mathrm{n})$

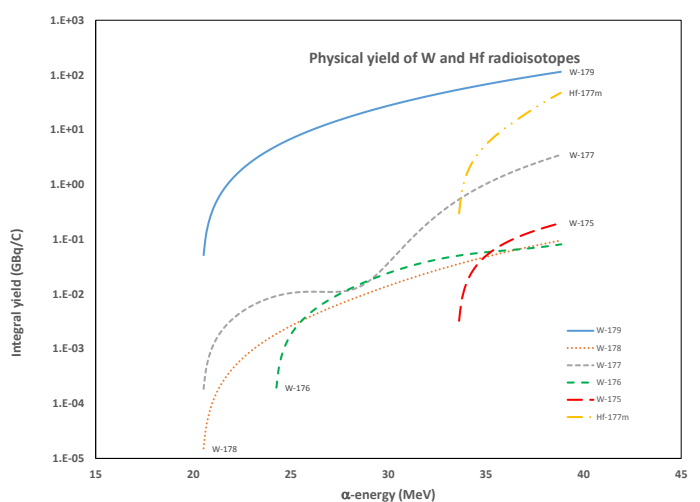

Figure 18: Integral yields for production of ${ }^{179,178,177,176,175} \mathrm{~W}$ and ${ }^{177 m} \mathrm{Hf}$ deduced from the excitation functions

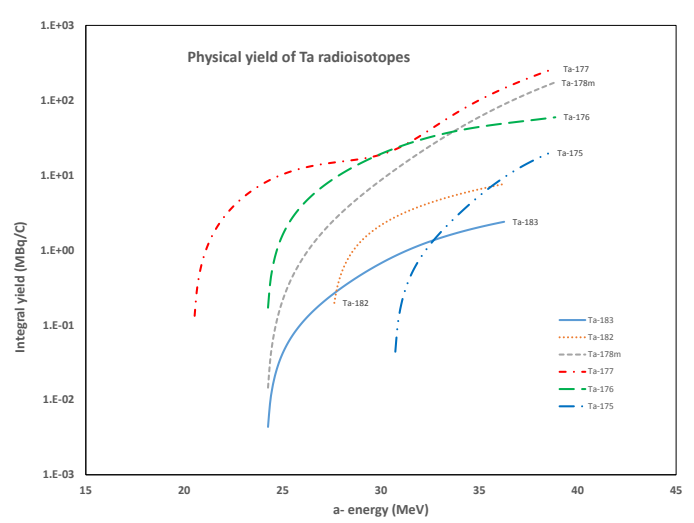

Figure 19: Integral yields for production of $183,182,178 m, 177,176,175 \mathrm{Ta}$ deduced from the excitation functions 


\section{Comparison of production routes of ${ }^{178} \mathrm{~W}$}

The medically interesting radionuclide ${ }^{178} \mathrm{~W}$ (parent in a ${ }^{178} \mathrm{~W} /{ }^{178} \mathrm{Ta}$ generator) can be produced in various ways:

- Proton and deuteron induced spallationevaporation on heavy mass targets.

- Proton induced route via the ${ }^{181} \mathrm{Ta}(\mathrm{p}, 4 \mathrm{n})$ reaction.

- Deuteron $(50 \mathrm{MeV})$ route via the ${ }^{181} \mathrm{Ta}(\mathrm{d}, 5 \mathrm{n})$ reaction.

- $\alpha$-particle (50-30 MeV incident energy) route via ${ }^{n a t} \operatorname{Hf}(\alpha, \mathrm{X})$ and ${ }^{176,177,178} \mathrm{Hf}(\alpha, \mathrm{xn})$ reactions.

- ${ }^{3} \mathrm{He}$ induced route via ${ }^{n a t} \mathrm{Hf}\left({ }^{3} \mathrm{He}, \mathrm{x}\right)$ and ${ }^{176,177,178} \mathrm{Hf}\left({ }^{3} \mathrm{He}, \mathrm{xn}\right)$ reactions.

Among these possibilities the low and medium energy routes (from point of view of the energy ranges of cyclotrons) were investigated also by us (the investigation of the ${ }^{3} \mathrm{He}$ process is in progress). While ${ }^{\text {nat }} \mathrm{Ta}$ is practically monoisotopic ( $\left.{ }^{181} \mathrm{Ta}-99.988 \%\right)$, hafnium has seven stable isotopes, (the isotopic compositions for hafnium and tantalum are shown in Table 2) and optimization of production may ask for enriched targets. In Fig. 23 the integral yield curves were calculated for the most promising reactions for each bombarding particles $\left(\mathrm{p}, \mathrm{d},{ }^{3} \mathrm{He}, \alpha\right)$. Each curve was calculated on the basis of the EMPIRE cross-section, taking into account a correction gained by comparison with the experimental data, except in the case of ${ }^{3} \mathrm{He}$, where no experimental data were available. The necessary corrections (based on a comparison with the experimental data) were in the range of $0.65-0.7$ in the three corrected cases, so we can suppose that the uncorrected ${ }^{3} \mathrm{He}$-induced yield is overestimated.

\subsection{Spallation-evaporation}

The ${ }^{178} \mathrm{~W}$ production using high energy particles was investigated through proton or deuteron induced high energy spallation on tantalum (Michel et al., 2001, Titarenko et al., 2011; Ur and Karamian, 2008), on mercury (Neuhausen et al., 2009) and on uranium (Casarejos et al., 2006). The nuclear data and the chemical separation process were investigated by the JINR (Russia group).

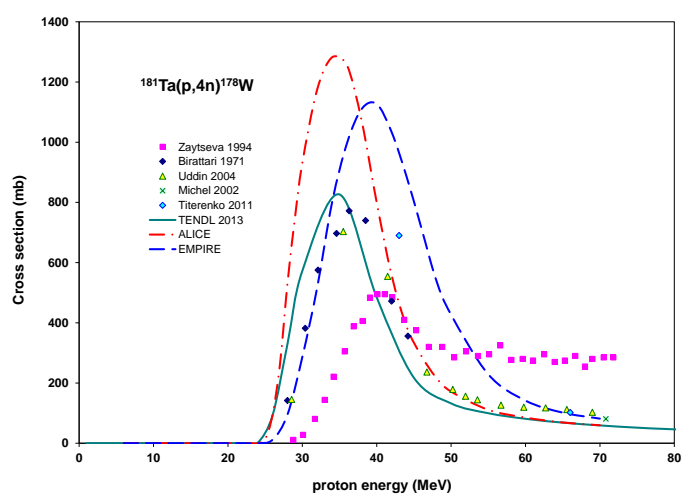

Figure 20: Experimental and theoretical excitation functions for ${ }^{181} \mathrm{Ta}(\mathrm{p}, 4 \mathrm{n}){ }^{178} \mathrm{~W}$

\section{2. ${ }^{181} \mathrm{Ta}(p, 4 n){ }^{178} \mathrm{~W}$ route}

Five experimental cross section data sets were found in the literature (see Fig. 20), reported by (Birattari et al., 1971), (Zaitseva et al. 1994), (Michel et al., 2001) (1 energy point), (Uddin et al. 2004) and (Titarenko et al., 2011) (2 energy points). The data of the high energy irradiations by Zaitseva and Titerenko show an upward energy shift near the maximum, probably due to the energy uncertainty at the end of a long stack. Moreover the data for the high energy cross section values of Zaitseva seem to be too high and the values at the maximum are too low. Most of routine productions at accelerators were made by using this reaction (Dmitriev et al., 1993, Pearce and Vincent, 1993).

\section{3. ${ }^{181} \mathrm{Ta}(d, 5 n)^{178} \mathrm{~W}$ route}

The experimental and theoretical results for the ${ }^{181} \mathrm{Ta}(\mathrm{d}, 5 \mathrm{n})$ reaction are presented in Fig. 17. In spite of the large cross sections no routine production was performed using this reaction, due to the high deuteron energy required. By comparing with the ${ }^{181} \mathrm{Ta}(\mathrm{p}, 4 \mathrm{n})$ reaction, the required incident particle energy is the same, the maximum cross sections are similar, but the yield for deuterons is expected to be lower due to the larger stopping power. Another point is, that in the case of commercial cyclotrons the maximum energy for deuterons is only $50 \%$ of the maximum energy for protons. No information is available on the real use of deuterons for production of ${ }^{178} \mathrm{~W}$.

\section{4. $176,177,178 H f(\alpha, x n)^{178} \mathrm{~W}$ route}

According to Fig. 3 the theoretical predictions for the ${ }^{n a t} \mathrm{Hf}(\alpha, \mathrm{x})$ reaction follow the shape of the experimen- 


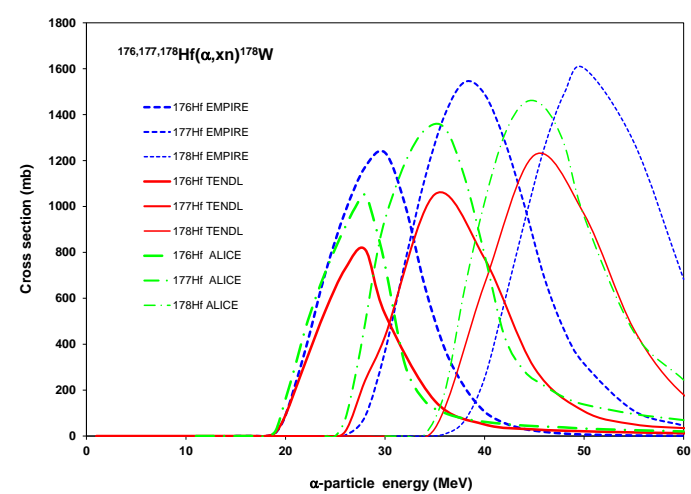

Figure 21: Theoretical excitation functions for (ALICE, EMPIRE, TENDL) ${ }^{176,177,178} \mathrm{Hf}(\alpha, \mathrm{xn})^{178} \mathrm{~W}$

tal data but the values are a little higher. In such a way, on the basis of this agreement we can predict the cross sections of the contributing reactions with high reliability. The theoretical data of contributing reactions from the TENDL-2013, ALICE and EMPIRE are shown in Fig. 21. Only a few routine productions by using alpha particle-induced reaction were already performed (Zaitseva and Dmitriev, 1999). As shown in Fig. 21, the maximum of the cross section and consequently the integral yield as a function of the number of emitted neutrons is rising with increasing energy. The comparison of the integral yields with the data on proton and deuteron induced reactions result in the well-known conclusion, that it requires the same energy range, but the yield of alpha induced reactions is lower (Fig. 23).

\section{5. ${ }^{176,177,178,179} \mathrm{Hf}\left({ }^{3} \mathrm{He}, \mathrm{xn}\right)$ route}

The theoretical excitation functions (Fig. 22) of the ${ }^{3} \mathrm{He}$-induced reactions show that the cross sections and consequently the yields (Fig.23) are significantly lower compared to the previous reactions, not to mention the high price of the ${ }^{3} \mathrm{He}$ gas for the ion source.

\subsection{Other factors influencing the choice of production route}

In the comparison above we compared only the production cross sections and yields. Other important factors should also be discussed, such as target price, target recovery (if necessary), the availability and the price of the bombarding beam, the radionuclide purity, specific activity, etc.:

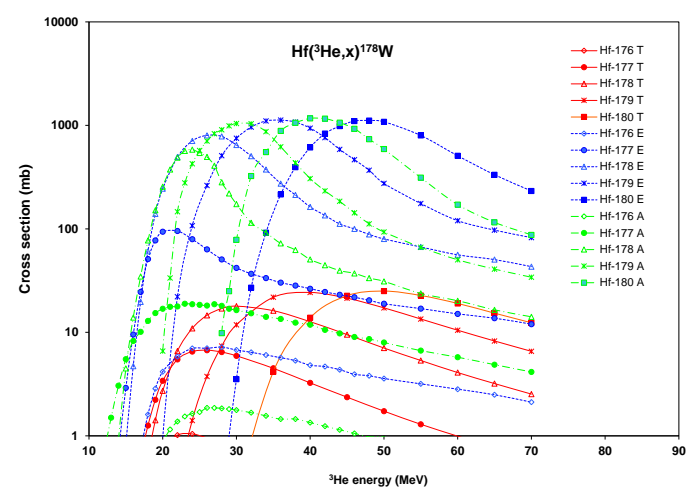

Figure 22: Theoretical excitation functions for (ALICE, EMPIRE, TENDL) ${ }^{176,177,178,179,180} \mathrm{Hf}\left({ }^{3} \mathrm{He}, \mathrm{xn}\right){ }^{178} \mathrm{~W}$

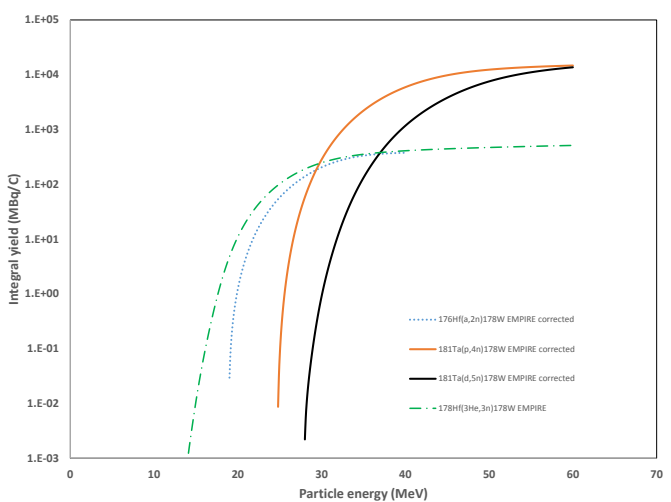

Figure 23: Comparison of the integral yield for the ${ }^{178} \mathrm{~W}$ producing proton, deuteron, ${ }^{3} \mathrm{He}$ and $\alpha$-induced reactions on different target isotopes 
Spallation requires high energy accelerators, allows use of large mass targets with natural isotopic composition resulting in a large number of radio-products, requiring complicated radiochemical processes for separation and purification. Due to the high energy reactions the target can be placed in the beam dump or tandem targets can be used.

The proton induced reaction on tantalum requires incident energy up to $70 \mathrm{MeV}$ for high yield. Nowadays $70 \mathrm{MeV}$, high intensity cyclotrons are to be installed in a few institutes. Cheap natural Ta targets can be used that can withstand high intensity beams. High-purity ${ }^{178} \mathrm{~W}$ production (target material and construction, separation chemistry) was investigated by (Dmitriev et al., 1997).

The optimal energy range for the deuteron route (70$35 \mathrm{MeV}$ ) is currently not available for accelerators for routine production. Although the targetry is practically the same as for the proton route, the yield is in any case lower.

Alpha induced reactions on hafnium have only one advantage, namely the ${ }^{176} \mathrm{Hf}(\alpha, 2 \mathrm{n})$ reaction $(30-20$ $\mathrm{MeV}$ ) could be implemented at low energy accelerators (for example at commercially available $30 \mathrm{MeV}$ $\mathrm{H}^{-}$cyclotrons having the alpha option for production of ${ }^{211} \mathrm{At}$ ). The production yield will be lower (compared to the proton and deuteron routes) and the targetry is more complicated as a highly enriched target is needed (price, recovery and target preparation). By using ${ }^{n a t} \mathrm{Hf}$ targets the yield will be about 20 times lower, but the targetry is simpler. Another issue is that the thermal conductivity of the metal hafnium is 2.5 times lower compared to tantalum, and also the maximum beam intensity of the alpha beams is significantly lower than proton intensity at commercial cyclotrons.

The ${ }^{3} \mathrm{He}$-induced reactions are not competitive. They can be used at low energy accelerators but the yield is very low even when using enriched targets. The targetry needed is the same as for $\alpha$-particles. The price of the ${ }^{3} \mathrm{He}$ gas for ion source is however high, even by using a ${ }^{3} \mathrm{He}$ recovery system. Recently built commercial cyclotrons have no ${ }^{3} \mathrm{He}$ options.

\section{Summary and conclusion}

We present experimental cross sections for the $\left.{ }^{n a t} \mathrm{Hf}(\alpha, \mathrm{X})\right)^{179,178,177,176,175} \mathrm{~W}, \quad 183,182,178 g, 177,176,175 \mathrm{Ta}$, ${ }^{179 m, 177 m, 175} \mathrm{Hf}$ reactions up to $39 \mathrm{MeV} \alpha$-particle energy for the first time, and new results for the ${ }^{181} \mathrm{Ta}(\mathrm{d}, 5 \mathrm{n})$ reaction up to $40 \mathrm{MeV}$. Our excitation functions are correlated to the ${ }^{n a t} \mathrm{Ti}(\alpha, \mathrm{x})^{51} \mathrm{Cr}$ and ${ }^{27} \mathrm{Al}(\mathrm{d}, \mathrm{x})^{24} \mathrm{Na}$ monitor reactions measured simultaneously over the whole covered energy range. The new experimental data are compared with the results of the ALICE-IPPE, EMPIRE and TALYS (TENDL2013) nuclear reaction model codes, and in the case of ${ }^{181} \mathrm{Ta}(\mathrm{d}, 5 \mathrm{n})$ reaction also with the results of an earlier measurement in the literature. The theoretical description of experimental data is acceptable by using standard parameters. The light ion activation routes of the ${ }^{178} \mathrm{~W}$ for production of the medically related ${ }^{178} \mathrm{~W} /{ }^{178} \mathrm{Ta}$ generator are compared, showing that in the medium energy range the ${ }^{181} \mathrm{Ta}(\mathrm{p}, 4 \mathrm{n})$, at low energies the ${ }^{176} \mathrm{Hf}(\alpha, 2 \mathrm{n})$ reactions are the favorite routes.

\section{Acknowledgements}

This work was performed in the frame of the HASFWO Vlaanderen (Hungary-Belgium) project. The authors acknowledge the support of the research project and of the respective institutions in providing the beam time and experimental facilities.

\section{References}

Belgya, T., Bersillon, O., Capote, R., Fukahori, T., Zhigang, G., Goriely, S., Herman, M., Ignatyuk, A. V., Kailas, S., Koning, A., Oblozinsky, P., Plujko, V., Young, P., 2005. Handbook for calculations of nuclear reaction data: Reference Input Parameter Library. http://www-nds.iaea.org/RIPL-2/. IAEA, Vienna.

Birattari, C., Gadioli, E., Strini, A. M. G., Strini, G., Tagliaferri, G., Zetta, L., 1971. (p, xn) reactions induced in 169tm, 181ta and 209bi with 20 to 45 mev protons. Nuclear Physics A 166 (3), 605623.

Bisplinghoff, J., Ernst, J., Mayer-kuckuk, T., Jahn, P., Mayer-Bricke, C., 1974. Analysis of (particle, $x n$ ) reactions on tantalum and gold: (iii). excitation functions of d-induced reactions on 181 ta from 10 to $80 \mathrm{mev}$ and equilibrium statistical analysis. Nuclear Physics A 228, 180-188.

Bonardi, M., 1987. The contribution to nuclear data for biomedical radioisotope production from the milan cyclotron facility.

Canberra, 2000. http://www.canberra.com/products/radiochemistry_lab/genie-2000-software.asp.

Casarejos, E., Benlliure, J., Pereira, J., Armbruster, P., Bernas, M., Boudard, A., Czajkowski, S., Enqvist, T., Legrain, R., Leray, S., Mustapha, B., Pravikoff, M., Rejmund, F., Schmidt, K. H., Stephan, C., Taieb, J., Tassan-Got, L., Volant, C., Wlazlo, W., 2006. Isotopic production cross sections of spallation-evaporation residues from reactions of u-238(1a gev) with deuterium. Physical Review C 74 (4), 4612.

Dityuk, A. I., Konobeyev, A. Y., Lunev, V. P., Shubin, Y. N., 1998. New version of the advanced computer code alice-ippe. Tech. rep., IAEA.

Dmitriev, S. N., Khalkin, V. A., Oganessian, R. T., Gulbekyan, G. G., Onishchenko, L. M., Starodub, G. Y., Zaitseva, N. G., 1993. Possibility of producing some radionuclides for medicine using jinr accelerators. In: Dutto, C., Craddock, M. K. (Eds.), 13th International Conference on Cyclotrons and their Applications. World Scientific, Singapore, p. 213.

Dmitriev, S. N., Zaitseva, N. G., Starodub, G. Y., Maslov, O. D., Shishkin, S. V., Shishkina, T. V., Buklanov, G. V., Sabelnikov, 
A. V., 1997. High-purity radionuclide production: material, construction, target chemistry for al-26, ru-97, w-178, np-235, pu235,pu-237. Nuclear Instruments \& Methods in Physics Research Section a-Accelerators Spectrometers Detectors and Associated Equipment 397 (1), 125-130.

Firestone, R. B., Ekstrm, L. P., 2004. Www table of radioactive isotopes version 2.1.

Haji-Saeid, M., Pillai, M. R. A., Ruth, T. J., Schlyer, D. J., Van den Winkel, P., Vora, M. M., Capote Noy, R., Carroll, L., Clark, J. C., omor, J., Dehnel, M., Ferrieri, R., Finn, R. D., Fowler, J. S., Schueller, M. J., Trknyi, F., 2009. Cyclotron produced radionuclides: Physical characteristics and production methods. Tech. rep., IAEA.

Herman, M., Capote, R., Carlson, B. V., Oblozinsky, P., Sin, M., Trkov, A., Wienke, H., Zerkin, V., 2007. Empire: Nuclear reaction model code system for data evaluation. Nuclear Data Sheets 108 (12), 2655-2715.

Hermanne, A., Daraban, L., Tárkányi, F., Takács, S., Ditrói, F., Ignatyuk, A., Rebeles, R. A., Baba, M., 2009. Excitation functions for some $\mathrm{w}$, ta and hf radionuclides obtained by deuteron irradiation of ta-181 up to 40 mev. Nuclear Instruments \& Methods in Physics Research Section B-Beam Interactions with Materials and Atoms 267 (19), 3293-3301.

IAEA, 2014. Exfor database.

Koning, A. J., Hilaire, S., Duijvestijn, M. C., 2007. Talys-1.0.

Koning, A. J., Rochman, D., van der Marck, S., Kopecky, J., Sublet, J. C., Pomp, S., Sjostrand, H., Forrest, R., Bauge, E., Henriksson, H., Cabellos, O., Goriely, S., Leppanen, J., Leeb, H., Plompen, A., Mills, R., 2012. Tendl-2013: Talys-based evaluated nuclear data library.

Lacy, J. L., Nanavaty, T., Dai, D., Nayak, N., Haynes, N., Martin, C., 2001. Development and validation of a novel technique for murine first-pass radionuclide angiography with a fast multiwire camera and tantalum 178. Journal of Nuclear Cardiology 8 (2), 171-181.

Layne, W. W., Lacy, J. L., 1990. Tantalum-178-labeled radiopharmaceutical synthesis via the intermediate tantalum pentachloride a potential myocardial perfusion agent. In: Emran, Ali, M. (Ed.), New Trends in Radiopharmaceutical Synthesis, Quality Assurance, and Regulatory Control. Vol. XI. Plenum Press, New York, p. 520 .

Michel, R., Gloris, M., Protoschill, J., Herpers, U., Kuhnhenn, J., Sudbrock, F., Malmborg, P., Kubik, P., 2001. Cross sections for the production of radionuclides by proton-induced reactions on $\mathrm{w}$, ta, pb and bi from thresholds up to 2.6 gev. In: Shibata, K. (Ed.), Intern.Conf.Nuclear Data for Science and Technology (ND2001). Vol. 1. Atomic Energy Society of Japan, p. 242.

Neuhausen, J., Schumann, D., Dressler, R., Horn, S., Lthi, S., Heinitz, H., Chiriki, S., Stora, T., Eller, M., 2009. Eurisol ds project task 2: Multi mw target station deliverable nd 2 innovative waste management in the liquid hg-loop.

Nichols, A. L., 2013. , +, and auger-electron decay data in nuclear medicine experimental determination, status and deficiencies ,. In: ICTP-IAEA Joint Workshop on Nuclear Data for Science and Technology: Medical Applications.

NuDat, 2014. Nudat2 database http://www.nndc.bnl.gov/nudat2/.

of-Weights-and Measures, I.-B., 1993. Guide to the expression of uncertainty in measurement, 1st Edition. International Organization for Standardization, Genve, Switzerland.

Pearce, D. R., Vincent, L. S., 1993. A facility for radioisotope production at triumf with 70-110 mev protons. In: 13th International Conference on Cyclotrons and their Applications. World Scientific, Singapore, p. 209.

Pritychenko, B., Sonzogni, A., 2003. Q-value calculator, http://www.nndc.bnl.gov/qcalc.
Semenov, L. B., Semenov, V. G., Semenova, M. P., Sobolevsky, N. M., 1996. Interactions of a Particles with targets from Sr to Cf. Vol. Landolt-Bornstein New Series Group I12H. Springer, Berlin.

Sonck, M., VanHoyweghen, J., Hermanne, A., 1996. Determination of the external beam energy of a variable energy. multiparticle cyclotron. Applied Radiation and Isotopes 47 (4), 445-449.

Székely, G., 1985. Fgm - a flexible gamma-spectrum analysis program for a small computer. Computer Physics Communications 34 (3), 313-324.

Tárkányi, F., Szelecsényi, F., Takács, S., 1991. Determination of effective bombarding energies and fluxes using improved stacked-foil technique. Acta Radiologica, Supplementum 376, 72.

Tárkányi, F., Takács, S., Gul, K., Hermanne, A., Mustafa, M. G., Nortier, M., Oblozinsky, P., Qaim, S. M., Scholten, B., Shubin, Y. N., Youxiang, Z., 2001. Beam monitor reactions (chapter 4). charged particle cross-section database for medical radioisotope production: diagnostic radioisotopes and monitor reactions. Tech. rep., IAEA.

Titarenko, Y. E., Batyaev, V. F., Titarenko, A. Y., Butko, M. A., Pavlov, K. V., Florya, S. N., Tikhonov, R. S., Zhivun, V. M., Ignatyuk, A. V., Mashnik, S. G., Leray, S., Boudard, A., Cugnon, J., Mancusi, D., Yariv, Y., Nishihara, K., Matsuda, N., Kumawat, H., Mank, G., Gudowski, W., 2011. Measurement and simulation of the cross sections for nuclide production in w-nat and ta-181 targets irradiated with 0.04- to 2.6-gev protons. Physics of Atomic Nuclei 74 (4), 551-572.

Uddin, M. S., Hagiwara, M., Kawata, N., Itoga, T., Hirabayashi, N., Baba, M., Tárkányi, F., Ditrói, F., Csikai, G., 2004. Measurement of excitation functions of the proton-induced activation reactions on tantalum in the energy range $28-70 \mathrm{mev}$. Journal of Nuclear Science and Technology, Supplement 4, 160.

Ur, C. A., Karamian, S. A., 2008. Spallation with intermediate energy protons as source of long-lived isomers. Romanian Reports in Physics 60 (3), 539-554.

Wilson, R. A., Kopiwoda, S. Y., Callahan, R. J., Moore, R. H., Boucher, C. A., Manspeaker, H., Castronovo, F. P., Strauss, H. W., 1987. Biodistribution of ta-178 - a short-lived radiopharmaceutical for blood pool imaging. European Journal of Nuclear Medicine 13 (2), 82-85.

Zaitseva, N. G., Dmitriev, S. N., 1999. Radiochemical separation methods for preparation of biomedical cyclotron radionuclides. Czechoslovak Journal of Physics 49, 825-829.

Zaitseva, N. G., Rurarz, E., Khalkin, V. A., Stegailov, V. I., Popinenkova, L. M., 1994. Excitation-function for $\mathrm{w}-178$ production in the ta-181(p,4n)w-178 reaction over proton energy-range 28.8-71.8 mev. Radiochimica Acta 64 (1), 1-6.

Ziegler, J. F., 1977. Helium : stopping powers and ranges in all elemental matter. The Stopping and ranges of ions in matter. Pergamon Press, New York. 
Table 3: Decay characteristics of the reaction products of the ${ }^{n a t} \mathrm{Hf}(\mathrm{a}, \mathrm{x}){ }^{179,178,177,176,175} \mathrm{~W},{ }^{183,182,178 g, 177,176,175} \mathrm{Ta},{ }^{179 m, 177 m, 175} \mathrm{Hf}$ and ${ }^{n a t} \mathrm{Ta}(\mathrm{d}, \mathrm{xn}){ }^{178} \mathrm{~W}$ investigated reactions and Q-values of reactions for their productions

\begin{tabular}{|c|c|c|c|c|c|}
\hline \multicolumn{6}{|c|}{${ }^{n a t} \mathbf{H f}(\alpha, \mathbf{x})^{179,178,177,176,175} \mathbf{W},{ }^{183.182,178 g, 177,176,175} \mathbf{T a},{ }^{179 m, 177 m, 175} \mathbf{H f}$} \\
\hline Nuclide & Half-life & $\mathrm{E}_{\gamma}(\mathrm{keV})$ & $I_{\gamma}(\%)$ & Contributing reaction & $\begin{array}{l}\text { Q-value } \\
(\mathrm{keV})\end{array}$ \\
\hline $\begin{array}{l}{ }^{179} \mathbf{W} \\
\varepsilon: 100 \%\end{array}$ & $37.05 \min$ & 133.9 & 0.106 & $\begin{array}{l}176 \mathrm{Hf}(\alpha, \mathrm{n}) \\
1777_{\mathrm{Hf}(\mathrm{a}, 2 \mathrm{n})} \\
178 \mathrm{Hf}(\alpha, 3 \mathrm{n}) \\
{ }^{179} \mathrm{Hf}(\mathrm{a}, 4 \mathrm{n}) \\
{ }^{180} \mathrm{Hf}(\mathrm{a}, 5 \mathrm{n})\end{array}$ & $\begin{array}{l}-10927.4 \\
-17303.3 \\
-24929.3 \\
-31028.3 \\
-38416.1\end{array}$ \\
\hline $\begin{array}{l}{ }^{178} \mathbf{W} \\
\varepsilon: 100 \%\end{array}$ & $21.6 \mathrm{~d}$ & $\begin{array}{l}\text { The } \gamma \text {-lines of the short- } \\
\text { lived }{ }^{178 g} \text { Ta were used }\end{array}$ & & $\begin{array}{l}176 \mathrm{Hf}(\alpha, 2 \mathrm{n}) \\
1777 \mathrm{Hf}(\alpha, 3 \mathrm{n}) \\
178 \mathrm{Hf}(\alpha, 4 \mathrm{n}) \\
{ }^{179} \mathrm{Hf}(\alpha, 5 \mathrm{n}) \\
{ }^{180} \mathrm{Hf}(\alpha, 6 \mathrm{n})\end{array}$ & $\begin{array}{l}-17886.8 \\
-24262.7 \\
-31888.7 \\
-37987.7 \\
-45375.4\end{array}$ \\
\hline $\begin{array}{l}{ }^{177} \mathbf{W} \\
\varepsilon: 100 \%\end{array}$ & $132 \mathrm{~min}$ & $\begin{array}{l}115.05 \\
115.65 \\
186.2 \\
186.42 \\
426.98 \\
1036.4\end{array}$ & \begin{tabular}{l|}
8.0 \\
47 \\
15.0 \\
7.3 \\
12.3 \\
9.5
\end{tabular} & $\begin{array}{l}{ }^{174} \mathrm{Hf}(\alpha, \mathrm{n}) \\
{ }^{176} \mathrm{Hf}(\alpha, 3 \mathrm{n}) \\
{ }^{177} \mathrm{Hf}(\alpha, 4 \mathrm{n}) \\
{ }^{178} \mathrm{Hf}(\alpha, 5 \mathrm{n}) \\
{ }^{179} \mathrm{Hf}(\alpha, 6 \mathrm{n}) \\
{ }^{180} \mathrm{Hf}(\alpha, 7 \mathrm{n})\end{array}$ & $\begin{array}{l}-11791.3 \\
-26665.8 \\
-33041.7 \\
-40667.6 \\
-46766.6 \\
-54154.4\end{array}$ \\
\hline $\begin{array}{l}{ }^{176} \mathbf{W} \\
\varepsilon: 100 \%\end{array}$ & $2.5 \mathrm{~h}$ & 100.20 & 100 & $\begin{array}{l}174 \mathrm{Hf}(\mathrm{a}, 2 \mathrm{n}) \\
{ }^{176} \mathrm{Hf}(\mathrm{a}, 4 \mathrm{n}) \\
\left.177 \mathrm{Hf}^{1} \mathrm{a}, 5 \mathrm{n}\right) \\
{ }^{178} \mathrm{Hf}(\mathrm{a}, 6 \mathrm{n}) \\
{ }^{179} \mathrm{Hf}(\mathrm{a}, 7 \mathrm{n}) \\
{ }^{180} \mathrm{Hf}(\mathrm{a}, 8 \mathrm{n})\end{array}$ & $\begin{array}{l}-18922.8 \\
-33797.2 \\
-40173.1 \\
-47799.1 \\
-53898.1 \\
-61285.8\end{array}$ \\
\hline $\begin{array}{l}175 \mathrm{~W} \\
\varepsilon: 100 \%\end{array}$ & $35.2 \mathrm{~min}$ & $\begin{array}{l}166.69 \\
270.25\end{array}$ & $\begin{array}{l}9.0 \\
12.6\end{array}$ & $\begin{array}{l}174 \mathrm{Hf}(\alpha, 3 \mathrm{n}) \\
{ }^{176} \mathrm{Hf}(\alpha, 5 \mathrm{n}) \\
{ }^{177} \mathrm{Hf}(\alpha, 6 \mathrm{n}) \\
{ }^{178} \mathrm{Hf}(\alpha, 7 \mathrm{n}) \\
{ }^{179} \mathrm{Hf}(\alpha, 8 \mathrm{n}) \\
{ }^{180} \mathrm{Hf}(\alpha, 9 \mathrm{n})\end{array}$ & $\begin{array}{l}-28002.9 \\
-42877.3 \\
-49253.2 \\
-56879.2 \\
-6279.2 \\
-70366.0\end{array}$ \\
\hline $\begin{array}{l}{ }^{183} \mathbf{T a} \\
\beta^{-}: 100 \%\end{array}$ & $5.1 \mathrm{~d}$ & $\begin{array}{l}107.9318 \\
246.0587 \\
353.9904\end{array}$ & $\begin{array}{l}11.0 \\
27 \\
11.2\end{array}$ & ${ }^{180} \mathrm{Hf}(\mathrm{a}, \mathrm{p})$ & -9349.74 \\
\hline $\begin{array}{l}{ }^{182} \mathbf{T a} \\
\beta^{-}: 100 \%\end{array}$ & $114.74 \mathrm{~d}$ & $\begin{array}{l}100.10595 \\
1121.290 \\
1189.040 \\
1221.395 \\
1231.004 \\
\end{array}$ & $\begin{array}{l}14.20 \\
35.24 \\
16.49 \\
27.23 \\
11.62 \\
\end{array}$ & $\begin{array}{l}{ }^{179} \mathrm{Hf}(\mathrm{a}, \mathrm{p}) \\
{ }^{180} \mathrm{Hf}(\mathrm{a}, \mathrm{pn})\end{array}$ & $\begin{array}{l}-8896.16 \\
-16283.92\end{array}$ \\
\hline $\begin{array}{l}178 g_{\mathbf{T a}} \\
\varepsilon: 98.76 \% \\
\beta^{+} 1.24 \%\end{array}$ & $9.31 \mathrm{~min}$ & $\begin{array}{l}93.13 \\
1106.09 \\
1340.85 \\
1350.55\end{array}$ & $\begin{array}{l}6.6 \\
0.54 \\
1.03 \\
1.18\end{array}$ & $\begin{array}{l}176 \mathrm{Hf}(\alpha, \mathrm{pn}) \\
177 \mathrm{Hf}(\alpha, \mathrm{p} 2 \mathrm{n}) \\
{ }^{178} \mathrm{Hf}(\alpha, \mathrm{p} 3 \mathrm{n}) \\
{ }^{179} \mathrm{Hf}(\alpha, \mathrm{p} 4 \mathrm{n}) \\
{ }^{180} \mathrm{Hf}(\alpha, \mathrm{p} 5 \mathrm{n}) \\
{ }^{178} \text { W decay }\end{array}$ & $\begin{array}{l}-16912.8 \\
-23288.7 \\
-30914.7 \\
-37013.7 \\
-44401.4\end{array}$ \\
\hline $\begin{array}{l}{ }^{178 m} \mathbf{T a} \\
\beta^{+}: 100 \%\end{array}$ & $2.36 \mathrm{~h}$ & $\begin{array}{l}213.440 \\
325.562 \\
331.613 \\
426.383\end{array}$ & $\begin{array}{l}81.4 \\
94 \\
31.19 \\
97.0\end{array}$ & $\begin{array}{l}{ }^{176} \mathrm{Hf}(\mathrm{a}, \mathrm{pn}) \\
{ }^{177} \mathrm{Hf}(\alpha, \mathrm{p} 2 \mathrm{n}) \\
178 \mathrm{Hf}(\alpha, \mathrm{p} 3 \mathrm{n}) \\
{ }^{179} \mathrm{Hf}(\alpha, \mathrm{p} 4 \mathrm{n}) \\
{ }^{180} \mathrm{Hf}(\alpha, \mathrm{p} 5 \mathrm{n})\end{array}$ & $\begin{array}{l}-16912.8 \\
-23288.7 \\
-30914.7 \\
-37013.7 \\
-44401.4\end{array}$ \\
\hline $\begin{array}{l}{ }^{177} \mathbf{T a} \\
\varepsilon: 100 \%\end{array}$ & $56.56 \mathrm{~h}$ & $\begin{array}{l}112.9 \\
208.4 \\
745.9 \\
1057.8\end{array}$ & $\begin{array}{l}7.2 \\
0.94 \\
0.21 \\
0.29\end{array}$ & $\begin{array}{l}174 \mathrm{Hf}(\alpha, \mathrm{p}) \\
176 \mathrm{Hf}(\alpha, \mathrm{p} 2 \mathrm{n}) \\
177{ }^{17 \mathrm{Hf}(\alpha, \mathrm{p} 3 \mathrm{n})} \\
{ }^{178} \mathrm{Hf}(\alpha, \mathrm{p} 4 \mathrm{n}) \\
{ }^{179} \mathrm{Hf}(\alpha, \mathrm{p} 5 \mathrm{n}) \\
{ }^{180} \mathrm{Hf}(\alpha, \mathrm{p} 6 \mathrm{n}) \\
{ }^{177} \mathrm{~W} \text { decay }\end{array}$ & $\begin{array}{l}-8993.6 \\
-23868.17 \\
-30244.02 \\
-37869.97 \\
-43968.96 \\
-51356.73\end{array}$ \\
\hline $\begin{array}{l}176 \mathbf{T a} \\
\varepsilon: 99.11 \% \\
\beta^{+}: 0.89 \%\end{array}$ & $8.09 \mathrm{~h}$ & $\begin{array}{l}201.84 \\
710.50 \\
1159.30\end{array}$ & $\begin{array}{l}5.7 \\
5.4 \\
24.7\end{array}$ & $\begin{array}{l}174 \mathrm{Hf}(\alpha, \mathrm{pn}) \\
1766_{\mathrm{Hf}(\alpha, \mathrm{p} 3 \mathrm{n})} \\
177{ }^{\mathrm{Hf}(\alpha, \mathrm{p} 4 \mathrm{n})} \\
{ }^{178} \mathrm{Hf}(\alpha, \mathrm{p} 5 \mathrm{n}) \\
{ }^{179} \mathrm{Hf}(\alpha, \mathrm{p} 6 \mathrm{n}) \\
{ }^{180} \mathrm{Hf}(\alpha, \mathrm{p} 7 \mathrm{n}) \\
{ }^{176} \mathrm{~W} \text { decay }\end{array}$ & $\begin{array}{l}-17416.7 \\
-32291.1 \\
-38667.0 \\
-46293.0 \\
-52391.9 \\
-59779.7\end{array}$ \\
\hline $\begin{array}{l}{ }^{175} \mathbf{T a} \\
\varepsilon: 100 \%\end{array}$ & $10.5 \mathrm{~h}$ & $\begin{array}{l}207.4 \\
266.9 \\
348.5\end{array}$ & $\begin{array}{l}14.0 \\
10.8 \\
12.0\end{array}$ & $\begin{array}{l}174 \mathrm{Hf}(\alpha, \mathrm{p} 2 \mathrm{n}) \\
{ }^{176} \mathrm{Hff}(\alpha, \mathrm{p} 4 \mathrm{n}) \\
{ }^{177} \mathrm{Hf}(\alpha, \mathrm{p} 5 \mathrm{n}) \\
{ }^{178} \mathrm{Hf}(\alpha, \mathrm{p} 6 \mathrm{n}) \\
{ }^{179} \mathrm{Hf}(\alpha, \mathrm{p} 7 \mathrm{n}) \\
{ }^{180} \mathrm{Hf}(\alpha, \mathrm{prn}) \\
{ }^{175} \mathrm{~W} \text { decay }\end{array}$ & $\begin{array}{l}-24444.7 \\
-39319.1 \\
-45695.0 \\
-53321.0 \\
-59420.0 \\
-66807.8\end{array}$ \\
\hline $\begin{array}{l}179 m \mathbf{H f} \\
\text { IT: } 100 \% \\
1105.74 \mathrm{keV}\end{array}$ & $25.05 \mathrm{~d}$ & $\begin{array}{l}122.70 \\
146.15 \\
169.78 \\
192.66 \\
236.48 \\
268.85 \\
315.93 \\
362.55 \\
409.72 \\
453.59\end{array}$ & $\begin{array}{l}27.7 \\
27.1 \\
19.4 \\
21.5 \\
18.8 \\
11.3 \\
20.3 \\
39.6 \\
21.5 \\
68\end{array}$ & $\begin{array}{l}177 \mathrm{Hf}(\alpha, 2 \mathrm{p}) \\
178 \mathrm{Hf}(\alpha, 2 \mathrm{pn}) \\
{ }^{179} \mathrm{Hf}(\alpha, 2 \mathrm{p} 2 \mathrm{n}) \\
{ }^{180} \mathrm{Hf}(\alpha, 2 \mathrm{p} 3 \mathrm{n})\end{array}$ & $\begin{array}{l}-14570.71 \\
-22196.67 \\
-28295.66 \\
-35683.43\end{array}$ \\
\hline
\end{tabular}


Table 3: Table 3. continued

\begin{tabular}{|c|c|c|c|c|c|}
\hline \multicolumn{6}{|c|}{${ }^{{ }^{n a t}{ } \mathbf{H f}(\alpha, \mathbf{x}){ }^{179,178,177,176,175} \mathbf{W}, 183.182,178 g, 177,176,175} \mathbf{T a}^{1}{ }^{179 m, 177 m, 175} \mathbf{H f}$} \\
\hline Nuclide & Half-life & $\mathrm{E}_{\gamma}(\mathrm{keV})$ & $\mathrm{I}_{\gamma(\%)}$ & Contributing reaction & $\begin{array}{l}\text { Q-value } \\
(\mathrm{keV})\end{array}$ \\
\hline $\begin{array}{l}177 \mathrm{~m}^{2} \mathbf{H f} \\
\text { IT: } 100 \% \\
2740.0 \mathrm{keV}\end{array}$ & $51.4 \mathrm{~min}$ & $\begin{array}{l}214.0 \\
277.3 \\
295.1 \\
311.5 \\
326.7 \\
638.2 \\
\end{array}$ & $\begin{array}{l}42 \\
78 \\
72 \\
61 \\
68 \\
21.0\end{array}$ & $\begin{array}{l}{ }^{176} \mathrm{Hf}(\alpha, 2 \mathrm{pn}) \\
{ }^{177} \mathrm{Hf}(\alpha, 2 \mathrm{p} 2 \mathrm{n}) \\
178 \mathrm{Hf}(\alpha, 2 \mathrm{p} 3 \mathrm{n}) \\
{ }^{179} \mathrm{Hf}(\alpha, 2 \mathrm{p} 4 \mathrm{n}) \\
{ }^{180} \mathrm{Hf}(\alpha, 2 \mathrm{p} 5 \mathrm{n})\end{array}$ & $\begin{array}{l}-21919.75 \\
-28295.66 \\
-35921.62 \\
-42020.62 \\
-49408.38\end{array}$ \\
\hline $\begin{array}{l}{ }^{175} \mathbf{H f} \\
\varepsilon: 100 \%\end{array}$ & $70 \mathrm{~d}$ & 343.40 & 84 & $\begin{array}{l}174 \mathrm{Hf}(\alpha, 2 \mathrm{pn}) \\
{ }^{176} \mathrm{Hf}(\alpha, 2 \mathrm{p} 3 \mathrm{n}) \\
177 \mathrm{Hf}(\alpha, 2 \mathrm{p} 4 \mathrm{n}) \\
{ }^{178} \mathrm{Hf}(\alpha, 2 \mathrm{p} 5 \mathrm{n}) \\
{ }^{179} \mathrm{Hf}(\alpha, 2 \mathrm{p} 6 \mathrm{n}) \\
{ }^{180} \mathrm{Hf}(\alpha, 2 \mathrm{p} 7 \mathrm{n}) \\
{ }^{175} \mathrm{Ta} \text { decay }\end{array}$ & $\begin{array}{l}-21587.17 \\
-36461.59 \\
-42837.5 \\
-50463.46 \\
-56562.46 \\
-63950.22\end{array}$ \\
\hline \multicolumn{6}{|c|}{${ }^{n a t} \mathbf{T a}(\mathbf{d}, \mathbf{x n}){ }^{178} \mathbf{W}$} \\
\hline Nuclide & Half-life & $\mathrm{E}_{\gamma}(\mathrm{keV})$ & $I_{\gamma(\%)}$ & Contributing reaction & $\begin{array}{l}\begin{array}{l}\text { Q-value } \\
(\mathrm{keV})\end{array} \\
\end{array}$ \\
\hline $\begin{array}{l}{ }^{178} \mathbf{W} \\
\varepsilon: 100 \%\end{array}$ & $21.6 \mathrm{~d}$ & & & $\begin{array}{l}1800 \mathrm{Ta}(\mathrm{d}, 4 \mathrm{n}) \\
181 \mathrm{Ta}(\mathrm{d}, 5 \mathrm{n})\end{array}$ & $\begin{array}{l}-17676.4 \\
-25253.1\end{array}$ \\
\hline
\end{tabular}

When complex particles are emitted instead of individual protons and neutrons the Q-values have to be decreased by the respective binding energies of the compound particles: np-d: $2.2 \mathrm{MeV}$; $2 \mathrm{np}-\mathrm{t}: 8.48 \mathrm{MeV} ; 2 \mathrm{p} 2 \mathrm{n}-\mathrm{a}: 28.30 \mathrm{MeV}$

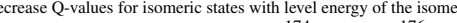

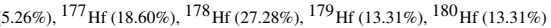
Abundance of isotopes in natural tantalum: ${ }^{180} \mathrm{Ta}(0.012 \%),{ }^{181} \mathrm{Ta}(99.988 \%)$

Table 4: Activation cross sections of tungsten radioisotopes in alpha particle induced reactions on hafnium

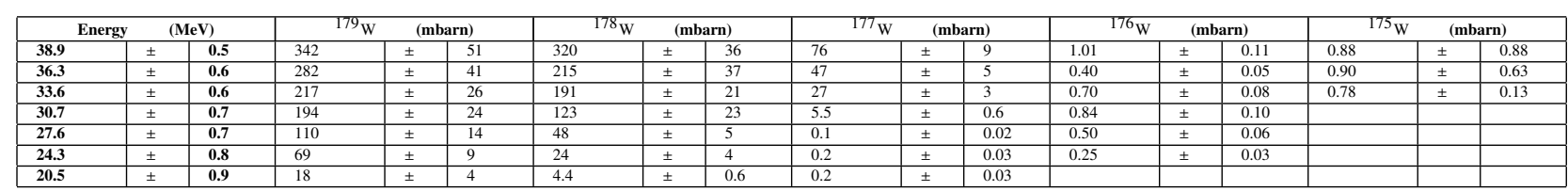

Table 5: Activation cross sections of tantalum radioisotopes in alpha particle induced reactions on hafnium

\begin{tabular}{|c|c|c|c|c|c|c|c|c|c|c|c|c|c|c|c|c|c|c|c|c|}
\hline Energy & & & ${ }^{183} \mathbf{T a}$ & & & ${ }^{182} \mathbf{T a}$ & & & ${ }^{178 m} \mathbf{T a}$ & & & ${ }^{177} \mathbf{T a}$ & & & ${ }^{176} \mathbf{T a}$ & & & ${ }^{175} \mathbf{T a}$ & & \\
\hline 38.9 & \pm & 0.5 & & \pm & & & \pm & & 3.8 & \pm & 0.4 & 125.9 & \pm & 14.3 & 1.5 & \pm & 0.2 & 1.9 & \pm & 0.4 \\
\hline 36.3 & \pm & 0.6 & 1.3 & \pm & 0.6 & 8.1 & \pm & 1.1 & 2.5 & \pm & 0.3 & 78.7 & \pm & 8.9 & 1.0 & \pm & 0.2 & 1.7 & \pm & 0.2 \\
\hline 33.6 & \pm & 0.6 & 1.4 & \pm & 0.3 & 5.1 & \pm & 0.8 & 1.2 & \pm & 0.1 & 65.3 & \pm & 7.4 & 1.8 & \pm & 0.2 & 0.6 & \pm & 0.1 \\
\hline 30.7 & \pm & 0.7 & 1.4 & \pm & 0.2 & 2.7 & \pm & 0.5 & 0.51 & \pm & 0.06 & 13.4 & \pm & 1.5 & 1.9 & \pm & 0.2 & 0.2 & \pm & 0.04 \\
\hline 27.6 & \pm & 0.7 & 0.5 & \pm & 0.3 & 0.2 & \pm & 0.3 & 0.17 & \pm & 0.02 & 3.1 & \pm & 0.4 & 1.3 & \pm & 0.2 & & & \\
\hline 24.3 & \pm & 0.8 & 0.3 & \pm & 0.1 & & & & 0.02 & \pm & 0.003 & 7.6 & \pm & 0.9 & 0.7 & \pm & 0.1 & & & \\
\hline 20.5 & \pm & 0.9 & & & & & & & & & & 4.2 & \pm & 0.5 & & & & & & \\
\hline
\end{tabular}

Table 6: Activation cross sections of hafnium radioisotopes in alpha particle induced reactions on hafnium and of the ${ }^{181} \mathrm{Ta}(\mathrm{d}, 5 \mathrm{n}){ }^{178} \mathrm{~W}$ reaction

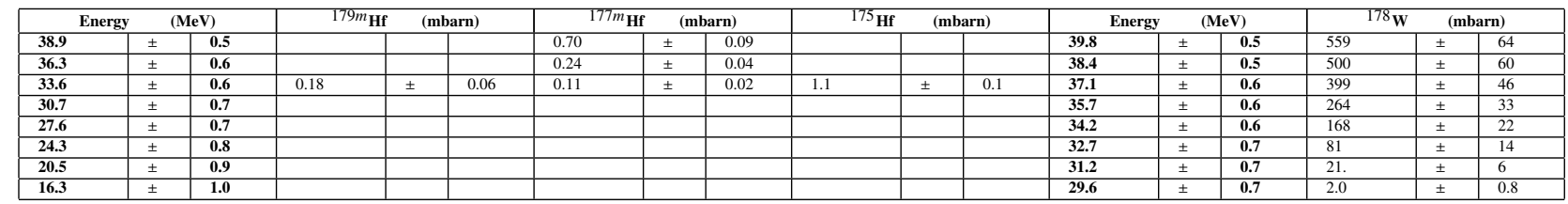

